\title{
Winner's Curse, Reserve Prices and Endogenous Entry: Empirical Insights from eBay Auctions
}

\author{
Patrick Bajari and Ali Hortaçsu* \\ Department of Economics \\ Stanford University
}

January 13,2000

\begin{abstract}
Online auctions have recently gained widespread popularity and are one of the most successful forms of electronic commerce. We examine a dataset of eBay coin auctions to explore features of online bidding and selling behavior. We address three main issues. First, we measure the extent of the winner's curse. We find that for a representative auction in our sample, a bidder's expected profits fall by 3.2 percent when the expected number of bidders increases by one. Second, we document that costly entry is a key component in understanding observed bidding behavior. For a representative auction in our sample, a bidder requires $\$ 3.20$ of expected profit to enter the auction. Third, we study the seller's choice of reserve prices. We find that items with higher book value tend to be sold using a secret as opposed to posted reserve price with a low minimum bid. We find that this is, to a first approximation, consistent with maximizing behavior. We also develop new techniques for structurally estimating common value auction models.
\end{abstract}

\section{Introduction}

Auctions have found their way into millions of homes with the recent proliferation of auction sites on the Internet. The opportunity to study such online markets, especially the Web behemoth eBay, is doubtlessly a golden one for economists. eBay is a source for a large amount of high quality data and serves as a natural testing ground for existing theories of bidding and for market design issues in auctions.

Auctions are clearly one of the leading innovations of Internet commerce. The Economist reports that on a single day, eBay boasts some 2.4 million items for sale in over 1,500 unique categories

*E-mail: bajari@stanford.edu, hortacsu@stanford.edu. We would like to thank seminar participants at Caltech, University of Iowa, USC, Stanford, and SITE for their valuable comments. 
ranging from beanie babies, to art, to used computers. On the surface, online auction markets, such as eBay, appear to be a close approximation to an economist's idealization of a frictionless, competitive market where a large number of buyers and sellers engage in trade. The eBay community alone boasts some 3.8 million registered members. ${ }^{1}$

One factor that may inhibit efficient trade is private information. In Akerlof's celebrated lemon's example, hidden information can completely shut down markets. In an online auction, where items of unknown quality are being traded, buyers need to worry about overpaying for goods. Economists have recognized that there is a possibility of a winner's curse in auctions, namely, that bidders win items only because they pay too much. The winner's curse is more severe as the number of bidders becomes larger and, in a community of 3.8 million bidders, might be a factor that inhibits trade. Recently, leading theorists have suggested that information asymmetries and the winner's curse may inhibit efficient trade in online markets. ${ }^{2}$

One aim of this paper is to quantify the extent of the "winner's curse" on eBay. To do this, we chose the market for U.S. mint/proof coin sets. These coin sets are regarded as investment-grade collectibles and are traded in liquid resale markets. Hence a strong "winner's curse" effect maybe present in these auctions.

Another striking feature of auctions on eBay is that sellers are allowed some freedom in choosing the rules of the auction. Economic theorists have spent a great deal of time analyzing incentives and equilibrium under alternative auction rules. One form of rules we will focus on quite carefully is the choice of reserve price policy.

In an auction, a reserve price is the price below which the auctioneer refuses to sell the item. On eBay, we study two alternative forms of reserve prices. This first is that the seller can set a minimum bid for the auction, which is equivalent to what theorists typically call a posted reserve. Second, for an additional fee, sellers can use a hidden reserve price so that bidders are aware that a reserve is present, but do not know the value of the reserve at the time of bidding.

A large number of papers in economic theory, starting with Myerson (1981) and Milgrom and Weber (1982), have studied equilibrium in auctions with reserve prices and characterized the optimal reserve price policy. It can be shown that in the case of independent private values, the revenue maximizing mechanism involves a non-zero reserve price. In many real world auctions, including procurement, treasury bills, real estate and auction houses, both posted and hidden reserve prices are commonly used.

Despite the widespread use of reserve prices, there is, to the best of our knowledge, no systematic empirical work testing this large body of theory. The large volume of bidding data present on eBay allows us to study the reserve prices sellers choose in the data to test the theory. We find in the data, somewhat surprisingly, that high value items tend to use a secret reserve price with a low minimum bid while items with a low book value use only a posted reserve. There is no existing

\footnotetext{
${ }^{1}$ See The Economist, July 22, 1999, "The Heyday of the Auction."

2 "The Heyday of the Auction"
} 
theoretical model that has this prediction.

We believe the solution to the above puzzle relies on the fact that bidders choose which auction to attend. Our data set indicates quite clearly that setting a high minimum bid (public reserve price) deters bidders from participating in the auction. Studying the relationship between reserve prices and entry, however, comes at a cost: we have to build a realistic model of bidding with endogenous entry that we can take to the data.

The theoretical motivation for incorporating endogenous entry into models of bidding have previously been pointed out by Harstad (1990), and Levin and Smith (1994): Most celebrated results in auction theory, including the revenue ranking/equivalence theorems of Vickrey (1961), Milgrom and Weber (1982), and the optimal mechanism design literature assume that the number of bidders is fixed across the mechanisms they compare. However, in a setting like eBay, auctions of similar or even identical objects are listed side-by-side with differing bidding rules. Therefore if one set of auction rules promises higher expected profit to bidders than another, we would expect more bidders to enter the high-expected profit auction than the other, to the point that bidder rents are dissipated to a point of indifference. If there are enough potential bidders (millions on eBay), this point of indifference will be the cost of entry, which might be the cost of determining a sensible bid and the opportunity cost of time spent browsing the Internet. This means that not all bidder surplus is appropriated by the seller in terms of bidding proceeds, and hence the seller's revenue might depend on the amount of entry induced by the mechanism.

Empirical literature on auctions also takes the number of bidders at an auction as exogenously given. When, in the spirit of Paarsch (1992), Laffont, Ossard and Vuong (1995), or Elyakime, Laffont, Loisel and Vuong (1994), we estimate the distribution of valuations of a set of bidders from their observed bids, we implicitly condition on the fact that these bidders have rationally chosen to enter the auction while others from a larger population of potential bidders have not. And when we make policy recommendations based on these estimates, we typically assume that the same set of bidders will participate in the modified mechanism. If, however, modifying the mechanism affects the entry decisions, this will no longer be true.

To our knowledge, the only empirical work that recognizes the importance of accounting for endogenous entry is Paarsch (1997), who takes great care in identifying the set of potential bidders in the timber sale auctions he studies, and thus can account for the valuations of those who decided not to bid in a particular auction because they found the reserve price too high. We take Paarsch's lead further, and specify the process through which potential bidders enter the auction. Our structural model is also much more demanding than Paarsch's: whereas he focuses on the independent private values model, we use a common value model.

Estimating a model with common values and endogenous entry posses several technical difficulties. First, no previous estimation procedures can clearly be applied to the modeling framework we wish to study. One recent approach to estimation, suggested by Elyakime et al. (1994), requires 
that in the first order conditions, bidders private information can be represented as a function of the observed bid and the empirical probability distribution of bids. In our model, this condition fails because the valuation of the highest bidder cannot be recovered from the data when only the second highest price is observed. Another recent estimation procedure, suggested by Laffont et al. (1995) uses the fact that the expected revenue in a first price auction and second price auction are the same to formulate a method of moments estimation procedure. Laffont et al. (1995) argue that their procedure is desirable since it avoids the difficulty of computing equilibrium bid functions. In the case of eBay, however, the result that expected revenue is identical under alternative auction formats will fail because of the presence of common values.

The approach to estimation we take is most closely related to the work of Paarsch (1992) and Bajari (1997). An important step in the estimation procedure is to calculate the equilibrium bid functions efficiently. With common values, this may involve solving high dimensional integration problems that are computationally burdensome. An innovation of this paper is to realize, that in many cases, equilibrium bid function are "linearly scalable." That is if we make a linear transformation of the underlying valuations, a linear transformation of the bid function will be an equilibrium to the new game. This insight makes structural estimation of common value models computationally feasible. It is worth noting, that this insight can be employed in structural estimation of many other auction games, such a first price sealed bid auctions with private or common values, where computing the bid functions can be very expensive computationally.

Another problem for estimation of our model, as was first recognized by Donald and Paarsch (1993) is that the asymptotics for maximum likelihood estimation will not be straightforward because the support of the likelihood function depends on the parameter values. This is a generic problem in auction models. This paper will utilize Bayesian methods proposed first by Bajari (1997) to overcome this difficulty. While the problem we study in this paper is bidding in eBay auctions, the methods we propose are useful for estimation of other models that are difficult to compute.

The auction model we estimate generalizes previous estimation strategies in two ways. First, we are able to study a more general information structure in common value auctions. In Paarsch (1992), for example, the author is not able to recover the distribution of the unobserved common value component. This is because of the high dimensional integrals involved in computing the equilibrium. Our approach allows for the recovery of this common value component. Second, we estimate the unobserved entry process and its relation to the choice of minimum bid and reserve price policy.

The outline of the paper is as follows: we first give an overview of the market we're studying and present our data. We document several reduced form findings: bidding activity seems to be concentrated at the end of the auction, there is significant variation in the number of bidders who attend the auction, reduced form bid functions are decreasing in the number of bidders and reserve prices seem to have a strong impact on the number of bidders who participate in the auction. Also, 
sellers use secret reserves with low minimums for "big ticket" items and posted reserves for more mundane objects. We also note that reserve prices, as well as the number of bidders are likely to be endogenous and that compelling instruments do not exist. Therefore, we argue that a structural approach will be required to answer certain questions.

Second, after examining the reduced form evidence, we argue that a common values model with endogenous entry is the best description of the market that is computationally tractable. We derive the equilibrium to the model and discuss its properties. Third, we specify a structural model and describe how to estimate the model parameters.

Next, we summarize the parameter estimates from the structural model and discuss their economic interpretation. We then use our structural model to study a set of policy questions. First we measure the extent of the winner's curse in the market. This allows us to assess the claims that have been made by theorists that informational asymmetries may inhibit efficient trade in online auctions. Then we document that it is costly for bidders to enter the auction and measure the implicit costs of entry in this model. Finally, we simulate the seller's expected profits under alternative reserve price policies. We find that, to a first approximation, the observed behavior of the sellers appears to be optimal.

\section{Description of the market and data}

eBay is the premier auction site on the Internet. Since it was launched in 1995, it has captured a good share of the second-hand and collectible goods trade, and by the meteoric rise in its share price, has become one of the most successful and popular Internet companies. Furthermore, with thousands of browsable auctions closing each day, it is a goldmine for empirical research on auctions. However, since most items on eBay are second-hand goods or collectibles, they are very difficult to appraise by a non-specialist economist, and hence empirical testing of results from auction theory run into the difficulty of not being able to account for item-specific differences. Therefore, in this research, we focus on a market segment where a little reading about the market and consulting published price lists enable us to control for item-specific differences. This is the collectible coins market, which we describe briefly in the next section.

\subsection{The collectible coins market}

Coin collecting is a hobby with a long history and tradition. Aside from very rare coins from antiquity that can command hundreds of thousands or millions of dollars, even relatively modern coins find a market among the millions of coin collectors in the U.S. Recently, the trade in collectible coins has become an investment channel for many, especially after coins began to fetch astronomic prices in the 80s. Although these prices have come down in the last decade, many coin traders can 
be classified as speculators or at least collectors with strong investment motives. As such, the coin market is an interesting cross between durable goods markets and securities markets, which, from an auction theorists' perspective, boils down to a cross between private values and common values.

The traditional channels for trade in coins are retail collectors' shops or mail-order outlets. Many dealers and experienced collectors also attend regional coin shows or private auctions. On-line auction sites such as eBay are a promising new venue for coins trade; however, they still capture only a small part of the coin trade.

For this study, we focus on collectible mint/proof sets. Mint sets have been prepared by the Treasury for sale to collectors since 1947, and contain uncirculated specimens of each year's coins for every denomination issued from each mint. Proof sets are manufactured to have sharper details and a more-than-ordinary brilliance than mint sets. They also contain one of each denomination of the coins minted that year, and are once again sold directly from the government to collectors. These sets have been sold since 1936, and usually command a higher price than mint sets.

Since both mint and proof coins are uncirculated, the proper grading of the coins becomes less of an issue ${ }^{3}$, making them "well-defined products" for which a non-coin collecting econometrician can find price lists, unlike some specialty coins that would require an expert to appraise. A drawback to focusing on mint/proof sets is that post-1960 issues of these sets are fairly mundanely priced (some as low as $\$ 5-\$ 10)$, so the assumption of "bidder sophistication" may become somewhat suspect.

\section{2 eBay auctions}

Our data set contains the on-line auctions of U.S. mint/proof sets that were conducted between September 28 and October 2, 1998 at the eBay on-line auction site. In that period, about 100 auctions closed every day, though the volume has since increased to about 400 auctions per day. The auctions end 3, 5 or 7 days after they are listed. eBay only acts as an intermediary in these trades and does not handle the physical delivery of the goods. eBay's revenue comes from a fixed listing fee and a percentage of the transaction value if the auction is successful.

The bidding format used at eBay is a dynamic variant of the second-price sealed-bid auction, called "proxy bidding." Each bidder is asked to enter the maximum amount she is willing to pay. The eBay computer compares this value to the valuations submitted by other bidders. In case it is higher than existing valuations, the new bidder is designated as the "leading bidder." However, instead of the value entered by the bidder, only the amount that's necessary to outbid the bidder with the next highest value is displayed as the "leading bid." This also becomes the amount the bidder ends up paying if there are no other challengers. If the value is submitted by a new bidder

\footnotetext{
${ }^{3}$ According to the Official Red Book, since 1959, mint sets have been sealed in a protective plastic envelope. Proof sets also come in special plastic cases that protect them against tarnish. Some of the auction listings give additional information about the condition of the original casing, sometimes the original envelope or the casing is damaged or not available. But unless otherwise noted, the condition of the coins is taken to be "mint-state," the highest grade a coin can attain. We have also excluded reportedly self-assembled mint or proof sets, since these sets usually fetch much lower prices than original sets.
} 
is not high enough to lead the auction, or if the current auction leader is outbid, he's notified by e-mail and may revise his bid. Once an auction has concluded, the winner is notified by e-mail and it is up to him to contact the seller to arrange shipment and payment details. Most of the auctions that we study have shipping and handling fees preset by the seller, which is to be paid on top of the bid amount.

A seller on eBay is constrained to use the proxy bidding method ${ }^{4}$, but has a few options to customize the sale mechanism. She can set a minimum bid, or a secret reserve price ${ }^{5}$. The minimum bid is observed by all bidders; however, in a secret reserve price auction, bidders are only told whether the reserve price is met or not. The reserve price is not announced even after the auction ends.

Aside from choosing whether to use a secret reserve price, the seller can also pay eBay to advertise her auction as a "featured auction" for $\$ 99.95$ or a "category-featured auction" for $\$ 14.95$. None of the auctions in our dataset were featured auctions, which is understandable since the average value of the coins were about $\$ 25$.

Sellers can also differentiate themselves through eBay's innovative buyer/seller feedback system. eBay allows the buyer and the seller to rate their counterparts in transactions. The rating is in the form of a positive, negative or neutral response. Next to each buyer or seller's ID (which is usually a pseudonym or an e-mail address), the number of net positive responses is displayed. In order to prevent planted responses, only unique responses are factored into the reputation rating.

In addition to data downloadable from eBay pages, we found the book values for the auctioned items from the November 1998 issue of Coins magazine, which collects value estimates from coin dealers and coin auctions around the U.S. ${ }^{6}$

For each auction we collected the following variables:

1. SECRET: 1 for a secret reserve price auction, 0 if not.

2. SALE: 1 if the auction was successful, 0 if not.

3. BOOKVAL: bookvalue of object according to Coins magazine.

4. SHIPHAND: Shipping and handling fee (if reported by seller).

5. BLEMISH: 1 if the seller reports that there's a blemish in the object.

6. OVERALL: Overall reputation of seller (number of unique positive responses - number of unique negative responses).

7. NEGATIVE: Number of unique negative responses to seller.

\footnotetext{
4 "Dutch auctions" for the sale of multiple objects are also allowed, but we exclude such auctions from our study.

${ }^{5}$ The seller can still set a minimum bid in a secret reserve price auction.

${ }^{6}$ The November issue of the magazine was bought by one of the authors on October 22nd. We confirmed by e-maling the magazine that the prices quoted were market prices of mid-October. This is a reasonable time frame for resale, taking into account that it usually takes a week for the buyer to get the coins from a seller on Ebay.
} 
8. NBIDDER: Number of bidders.

9. AVGNBID is the average of bids in an auction as a percentage of bookvalue (conditional on there being at least one bidder).

10. DISPERSION is the difference between the maximum and the minimum bid as a percentage of bookvalue.

11. AVGFRAC is the average of bid submission times (as a fraction of auction duration).

12. AVGEXP is the average experience of bidders as measured by the number of previous transactions conducted on eBay.

13. MINBID: The minimum bid as set by the seller.

14. BID1N: The winning bid as a percentage of bookvalue (conditional on sale).

15. REVENUE: Revenue as a percentage of bookvalue (not conditional on sale).

16. BID1-BID25: Reported bids - which for every bidder except the winner corresponds to the submitted bid. BID1 is the amount paid by the winner, which is the bid increment plus the second bid. The bids are ranked in descending order.

17. FRAC1-FRAC25: Timing of final bid updates $^{7}$ - as a fraction of the total auction duration.

18. PREWIN1- PREWIN25: Previous wins of the bidder in eBay auctions - we use this variable as a proxy for bidder experience.

There were a total of 516 auctions completed in the mint-proof category in the five day sample we consider. We could not find reliable book values for 48 of the auctions and since the book value serves as our primary controlling variable for cross-object heterogeneity, we had to discard those observations from our data set (we checked whether this truncation makes any difference in the observed entry/reserve price setting behavior and could not find a noticeable pattern). 11 auctions were conducted as Dutch auctions and since those auctions are subject to a different set of rules, were omitted from our analysis. Detailed bid histories for 39 auctions were lost due to a technical error in data transfer. Aside from those, our dataset contains the entire set of mint-proof set auctions conducted during the dates considered.

We report summary statistics on the above variables in Table 1 . We see that $85 \%$ of the auctions resulted in a sale, with an average of 3 bidders per auction. The average value of the traded coins is $\$ 47$, with a $\$ 2$ shipping and handling charge. The coins range from $\$ 3$ to $\$ 3700$ in value, reflecting the wide dispersion of prices even within this relative narrow section of the collectible coin market. $10 \%$ of the coin sets had reported blemishes.

\footnotetext{
${ }^{7}$ Bidders have the ability to update their bids during the auction. What we have available in the "bid-history" pages on Ebay are the final bids by each buyer and the last time they updated their bids.
} 
Table 1: Summary Statistics

\begin{tabular}{||l||l||l||l||l||}
\hline \hline Variable & Mean & Std. & Min & Max \\
\hline \hline SECRET & .1606 & .3676 & 0 & 1 \\
\hline \hline SALE & .8513 & .3571 & 0 & 1 \\
\hline \hline BOOKVAL & 47.51 & 212.63 & 3 & 3700 \\
\hline \hline SHIPHAND & 2.18 & .92 & 1 & 5 \\
\hline \hline BLEMISH & .10 & .32 & 0 & 1 \\
\hline \hline OVERALL & 203.06 & 208.43 & 0 & 973 \\
\hline \hline NEGATIVE & .43 & 1.63 & 0 & 21 \\
\hline \hline NBIDDER & 3.05 & 2.46 & 0 & 14 \\
\hline \hline AVGNBID & 0.8354 & 0.2616 & 0.16 & 1.2824 \\
\hline \hline DISPERSION & 0.3215 & 0.2826 & 0 & 1.2333 \\
\hline \hline AVGFRAC & .70 & .25 & 0 & 1 \\
\hline \hline AVGEXP & 41.22 & 38.40 & 0 & 261.5 \\
\hline \hline MINBID & 16.28 & 28.59 & .01 & 230 \\
\hline \hline BID1N & 0.9556 & 0.2820 & 0.1600 & 1.4767 \\
\hline \hline REVENUE & 0.8135 & 0.4284 & 0 & 1.4767 \\
\hline \hline BID1 & 36.70 & 168.94 & 0 & 3010 \\
\hline \hline
\end{tabular}

Conditional on sale, revenues are $5 \%$ lower than the reported book values of the sample. However, not all items ended up being sold, so the expected average revenue from an auction, considering the possibility of no sale, was $81 \%$ of the bookvalue. The average bid in an auction was $83 \%$ of the bookvalue and the mean bid spread was $32 \%$ of the book value. There were quite a few outliers in the data: in 20 auctions, the winning bid was $50 \%$ above the bookvalue and in 5 auctions (all were posted reserve auctions), the winning bid was less than half the bookvalue. ${ }^{8}$

As for bidder and seller characteristics, we see that the average bidder has previously won 41 auctions and the average seller has done at least 203 transactions on eBay. Negative feedback points are very low compared to the positive feedback points of the sellers. ${ }^{9}$ We conclude from these observations that eBay is not just a marketplace for occasional hobbyists and that serious collectors and coin dealers are also participants.

\footnotetext{
${ }^{8}$ We checked these outliers to make sure there was not an error in coding the bookvalue. It's also interesting to note that 3 of the 5 low revenue auctions had more than one bidder.

${ }^{9}$ The maximum negative rating of 21 corresponds to the seller with the seller with 973 overall feedback points.
} 


\section{Empirical regularities}

In this section we report empirical regularities we observe in the data that we deem significant in formulating a model of bidding on eBay. We summarize the main findings of this section as the following:

1. We find that bidders update their bids frequently and that bidding activity is concentrated at the end of the auction. We also find that bid levels decline in the number of bidders in an auction. We conclude that a private values framework can not explain this kind of behavior and that a common values framework, with a potential "winner's curse" effect is better suited to model the auctions in our sample.

2. There is significant variation in the number of bidders in an auction. We find that a low minimum bid, a high bookvalue and low negative ratings increase entry to an auction.

3. Profit margins for bidders are slim and do not deviate significantly from book values of the coins once shipping and handling costs are accounted for.

4. The number of bids submitted in the auction is decreasing in the ratio of the minimum bid to the book value.

5. Sets with a high book value tend to be auctioned using a secret reserve price with a minimum bid that is significantly lower than the book value. Less expensive sets are auctioned using a posted reserve price with a higher minimum bid to book ratio.

6. Experience does not appear to play a significant role in bidding.

\subsection{Private vs. common values and the winner's curse}

How do bidders on eBay value the coin sets they are bidding on? One answer to this question is to say that each bidder (indexed by $i$ ) gets utility $v_{i}$ from winning the coin set. If the bidder $i$ knows $v_{i}$ (but not necessarily the $v$ 's of other bidders) we have the case of "private values."

"Private values" may make sense if the bidder is buying the coin set as a part of a collection. However, the existence of an active secondary market in collectible coins makes it quite plausible for bidders to have a resale incentive. The frequent activity of individual bidders on eBay suggests that quite a few of them could be dealers who make a living from buying and selling coins. If resale is the primary incentive, we can argue that all bidders get the same utility from winning the coin set; namely the resale value of the coin set. Here, $v_{i}=v$, the same number across all bidders. This is the case of (symmetric) "common values."

The problem with the "common values" case is that, typically the "resale" value $v$ is not known by the bidders. Rather than observing $v$, each bidder instead comes up with an "estimate" $x_{i}$, and 
bases her bid on this estimate. We can model this estimate as having the form $x_{i}=v+\varepsilon_{i}$, with $\varepsilon_{i}$ as a noise term. Now let's think whether a bidder would care to know about other bidders' estimates. If a bidder believes that $\varepsilon_{i}$ is truly an idiosyncratic noise term, then she can reduce the uncertainty of her estimate by averaging across all estimates. Through this averaging, a high estimate of the value of the object will be adjusted downwards, and a low estimate would be adjusted upwards.

Unfortunately, bidders rarely share their estimates. Here's where the "winner's curse" comes in: a bidder realizes that, conditional on winning, she must have had the highest estimate. ${ }^{10}$ Therefore, with some probability, she will have paid too much for the item. Observe that there is no room for a "winner's curse" in the private values setting. Each bidder is sure of the utility she will get from winning the auction, and does not have worry about whether she has understated or overstated this number ${ }^{11}$.

The "winner's curse" becomes worse as the number of bidders increases. The highest estimate among 15 bidders is very likely to be even higher than the highest estimate among 2 bidders. Therefore, we would expect bidders to be more afraid of a "winner's curse in a 15 person auction than in a 2 person auction; hence we would expect lower bids in a 15 person auction than in a 2 bidder auction ${ }^{12}$.

As first pointed out by Paarsch (1992), this last observation allows us to distinguish between a common values vs. a private values setting. Within the context of a second price auction or an ascending bid auction, such as the eBay auction, the number of bidders would have no effect on bids in a private values setting, since the dominant strategy in these auctions is to bid one's valuation. However, as will be noted more formally in the theory section, the common value model of eBay auctions predicts that bids will unambiguously decrease with an increase in the number of bidders.

To perform this test on our data set, we report in table 2 the regression of bids normalized by book value $(b)$ on the realized number of bidders $(N)$. We use the linear, quadratic and logarithmic specifications of Paarsch (1992) to check the robustness of our results. We see that for each specification, there is a significant negative relationship between the number of bidders and the normalized bid. This suggests the presence of common values over private values.

We also define the following measure for the winner's curse: the "winner's curse effect" is the percentage decline in bids in response to one additional bidder in the auction. If we take the linear

\footnotetext{
${ }^{10}$ To see why this is so, think of the case when each bidders estimate is unbiased. The unconditional mean of each estimate will be $v$, but the mean of the estimate conditional on the fact that it is the "maximum among $n$ " estimates will be greater than $v$.

${ }^{11}$ could argue that even in a private values setting, bidders do not observe $v_{i}$ until they receive the coin set and hence bid on the basis of an estimate $x_{i}=v_{i}+\varepsilon_{i}$. If the noise term ${ }_{i}$ is independent across bidders, then bidders have nothing to learn from other people's estimates, and there is no room for a "winner's curse." If, however, the noise term is somehow correlated across bidders, then a "winner's curse" still exists. Observe that this is observationally equivalent to a setting where the bidders valuation for the object has both a private and a common value component, where the private value component is $u_{i}$ and the bidder makes an estimate, $\chi_{i}=v+\xi_{i}$ about the unknown common value $v$ with noise $\xi_{i}$ (i.e. $x_{i}=u_{i}+v+\xi_{i}$, with the correlation captured by $v$ ).

${ }^{12}$ Though we could also expect that bidders would increase their bids in the face of increased competition, and that the effect of increasing the number of bidders on bid levels would be ambiguous. We will resolve this ambiguity in our model of bidding.
} 
Table 2: Regression of bid/bookval on the number of bidders

\begin{tabular}{||c||c||c||c||}
\hline \hline Specification & Linear & Quadratic & Logarithmic \\
\hline \hline & $b=\beta_{0}+\beta_{1} N$ & $b=\beta_{0}+\beta_{1} N+\beta_{2} N^{2}$ & $\ln (b)=\beta_{0}+\beta_{1} \ln N$ \\
\hline \hline$\beta_{0}$ & $.9836(.0202)$ & $1.0932(.0354)$ & $-.0420(.033)$ \\
\hline \hline$\beta_{1}$ & $-.0342(.0035)$ & $-.0804(.0128)$ & $-.0572(.005)$ \\
\hline \hline$\beta_{2}$ & N/A & $.0038(.0010)$ & N/A \\
\hline \hline$R^{2}$ & 0.0625 & 0.072 & 0.065 \\
\hline \hline
\end{tabular}

model at face value, the "winner's curse effect" can be quantified at about $3.4 \%$ of the bookvalue per additional bidder.

An important criticism that could be made of the regressions in Table 2 is that the number of bidders who participate in an auction is very likely to be endogenous. If the number of bidders is correlated with attributes of the auction that we have failed to model in our simple specification, then the estimate of the slope coefficient will be biased, making it difficult to assess the extent of the winner's curse from the above specification. Unfortunately, it is hard to think of natural instruments for the number of bidders, since factors correlated with the number of bidders should also enter into the distribution of valuations. We therefore take the evidence in table 2 as suggestive, as opposed to conclusive, about the impact of the number of bidders on the bid/bookval ratio. Also, in eBay, it is very hard for a bidder to know exactly how many competitors she is facing (since almost all the action transpires at the end of the auction); so the number of bidders we observe might not be the number of bidders that the bidder had in mind when forming her bid. We will attempt to address these issues more completely in sections 4 and 5 where we build and estimate a structural model of price formation in eBay.

We should note that on eBay there is an even simpler test to distinguish between a private values and a common values environment. Recall that in the "proxy-bidding" system, bidders can observe the bids of others at least until the very end of the auction and have the option to update their bids. The dominant strategy in this auction in a private values environment is to bid one's valuation, therefore it does not matter when a bid is placed. Furthermore, once a bid, presumably equal to the valuation of the bidder, is placed, it should not be necessary to change it.

Our data rejects both predictions of the private values setting. First, as we will show below, the bids are lumped disproportionately at the end of the auction. So it does matter when the bids are placed. In fact, we will show that bidding at the last minute turns out to be an equilibrium strategy under the common values model. Second, we find that bidders routinely update their bids. In our data, we can also observe how many total bids were submitted throughout the auction. In the set of auctions we consider, bidders submit on average 5.2 bids. With an average 3 bidders per auction, this means that almost every bidder updates her bid once. 


\subsection{Timing of bids}

Figure 1 is a histogram of final bid submission times. ${ }^{13}$ As one can see, more than $50 \%$ of final bids are submitted after $90 \%$ of the auction duration has passed. This corresponds to the last 7 hours of the auction in a 3 day auction. About $32 \%$ of the bids are submitted after $97 \%$ of the auction has passed, that is, the last 2 hours of a 3 day auction.

The winning bids tend to come even later. ${ }^{14}$ The median winning bid arrives after $98.3 \%$ of the auction time has elapsed (within the last 73 minutes of a 3 day auction), and $25 \%$ of the winning bids arrived after $99.8 \%$ of the auction time elapsed (the last 8 minutes of a 3 day auction).

The evidence shows that bidding activity is concentrated at the very end of the auction. As we explained in the section regarding common vs. private values, this finding can not be consistent with the presence of private values.

It is interesting to note that a private values framework is what eBay tries to instill in the bidders in its online bidding manual: in eBay's explanation of the proxy bidding system, the bidders are urged to decide on their private value, submit it online and wait until the conclusion of the auction. It is quite clear from the above evidence that bidders do not abide by eBay's recommendation, and, as we will show in section 4 , with good reason.

\subsection{Entry}

Since the previous section revealed that the number of competitors in an auction is an important determinant of bid levels, we ask the following question: what attracts bidders into an auction? In Table 3, we run a regression of the number of bidders on the minimum bid (normalized over book value), the reserve price policy (SECRET is a dummy for secret reserve price policy), the bookvalue of the item, and the negative reputation of the seller.

The minimum bid seems to be the single most important determinant of entry in our sample, regardless of there being a secret reserve price or not. The difference between setting the minimum bid equal to the bookvalue and at zero is almost 4 more bidders in the auction!

This finding is driven by the fact that the minimum bid censors the distribution of bidder valuations we observe. As we shall discuss below, in a common values setting, we will not observe bids from bidders whose signals are below a "screening-level," which is strictly above the minimum bid. The negative coefficient on the minbid/book could be due to two reasons. The first is we observe fewer bidders in the data because the reserve exceeded the bidder's maximum willingness to pay. A second is that high reserves discourage bidders from even attending the auction and investigating the value of the object. While this distinction may seem trivial at first, a number of theorists, including Harstad (1990) and Levin and Smith (1994) have argued that correctly accounting for the potential number of bidders is key in assessing the relationship between reserve prices and seller

\footnotetext{
${ }^{13}$ Recall that we track only the final bids of each bidder.

${ }^{14}$ The winning bid is not necessarily the latest.
} 
Table 3: Regression of the number of bidders on auction specific variables

\begin{tabular}{||l||l||l||l||}
\hline \hline NBIDDER & Coef. & Std. Err. & t-stat \\
\hline \hline${\text { (MINBID/BOOK })^{*} \text { SECRET }}^{*}$ & -3.7875 & 1.8886 & -3.187 \\
\hline \hline (MINBID/BOOK $^{*}(1$-SECRET $)$ & -3.6767 & .2378 & -15.457 \\
\hline \hline SECRET & .3840 & .4752 & 0.808 \\
\hline \hline LN(BOOK $)$ & .4576 & .0934 & 4.894 \\
\hline \hline BLEMISH & -.1354 & .3077 & -0.440 \\
\hline \hline NEGATIVE & -.1562 & .0542 & -2.879 \\
\hline \hline CONSTANT & 4.1218 & .3368 & 12.239 \\
\hline \hline$R^{2}$ & 0.5009 & & \\
\hline \hline
\end{tabular}

revenue. We will emphasize this distinction while building our structural model in sections 4 and 5 , where we find correctly accounting for the potential number of participants is key in understanding how sellers set their reserve prices.

We also find that the existence of a secret reserve price does not affect entry significantly. All things being equal, one might expect that a secret reserve price should deter entry, for rational bidders should realize that their chance of winning an auction with a secret reserve price is lower. The above finding appears to point out that either bidders' expectation of the secret reserve price, or that the cost of preparing and submitting a bid is low enough that it is worthwhile for bidders to enter an auction that they will most likely not win.

Aside from reserve price/minimum bid policy, the bookvalue also appears as a significant determinant of entry; however, the parameter estimate in Table 3 means that a ten-fold increase in bookvalue is needed to add another bidder to the auction. Also, a seller with negative feedback attracts fewer bidders ( 7 or 8 negative comments drive away one bidder).

Given that the minimum bid is by far the most important determinant of entry, what does the seller's choice of a minimum bid depend on? In table 4, we regress the minimum bid (normalized over book value) on SECRET, BLEMISH and the natural logs of OVERALL (which we take as a proxy for seller experience), NEGATIVE and BOOKVAL. We find that the seller's experience or reputation do not affect the choice of minimum bid. However, the minimum bid is decidedly lower if the seller is running a secret reserve price auction, or if the seller is running an ordinary (no secret reserve price) auction with a high book value.

One way to interpret the results in Table 4 is to say that sellers of high book value items are willing to risk selling the item for a low price in order to induce entry to their auctions. Their hope is that after at least two bidders have entered the auction, the bidding will reach a competitive level, provided that both bidders have valuations that are close to the book value of the item.

This argument is only true to a certain extent, however. For high book value items, sellers 
Table 4: Regression of minimum bid levels on auction specific regressors

\begin{tabular}{||c||c||c||c||}
\hline \hline MINBID/BOOK & Coef. & Std. Err. & t-stat \\
\hline \hline LN(OVERALL) & -.000376 & .0158 & -0.024 \\
\hline \hline LN(NEGATIVE) & -.03754 & .0408 & 0.920 \\
\hline \hline LN(BOOK $)^{*}$ SECRET & -.01376 & 0.028 & -0.479 \\
\hline \hline LN(BOOK) $(1-S E C R E T)$ & -.1102 & .02611 & -4.221 \\
\hline \hline SECRET & -.6531 & .1406 & -4.644 \\
\hline \hline BLEMISH & -.1033 & .0646 & -1.598 \\
\hline \hline CONSTANT & .9960 & .1078 & 9.085 \\
\hline$R^{2}$ & 0.1668 & & \\
\hline
\end{tabular}

Table 5: Quantiles of Book Value Across Auction Formats

\begin{tabular}{||l||l||l||}
\hline \hline Quantile & Secret Reserve & Posted Reserve \\
\hline \hline $5 \%$ & 4 & 4.75 \\
\hline \hline $10 \%$ & 6.75 & 6 \\
\hline \hline $25 \%$ & 9 & 8.5 \\
\hline \hline $50 \%$ & 42.5 & 13.5 \\
\hline \hline $75 \%$ & 148.5 & 22.25 \\
\hline \hline $90 \%$ & 620 & 41.25 \\
\hline \hline $95 \%$ & 910 & 56 \\
\hline \hline $99 \%$ & 3700 & 200 \\
\hline \hline
\end{tabular}

overwhelmingly favor a secret reserve price auction over an ordinary auction, as seen in Table 5 . Conducting a secret reserve price auction allows the seller to set a low minimum bid to attract entry, at the same time ensuring a high price conditional upon sale ${ }^{15}$. Unfortunately eBay does not divulge the secret reserve prices, therefore we can not compare the secret reserve price to minimum bid levels in ordinary auctions; however, the fact that far fewer secret reserve price auctions result in a sale $(50 \%$ vs. $84 \%)$ indicate that secret reserve price levels are higher than the minimum bids in ordinary auctions.

If secret reserve price auctions allow a seller to extract higher prices without discouraging entry, then why don't we see more frequent use of this mechanism (only 16\% of the auctions have a secret reserve price)? One answer to this question is that eBay charges sellers an extra $\$ 1$ for conducting a secret reserve price auction. This fee is refundable upon sale; however, one can see that the fee is designed to prevent sellers from setting a high reserve price and continually relisting their item

\footnotetext{
${ }^{15}$ In fact we have confirmed the use of this intuition by tuning into some bidder discussion groups on the eBay site.
} 
until a transaction occurs. Thus, for $\$ 5$ items it might not pay to use a secret reserve price, but for bigger-ticket items, the additional cost might be worth the revenue improvement ${ }^{16}$.

We should note that the above intuition runs counter to the only result we have been able to find in the auction theory literature regarding the use of secret reserve prices: Elyakime et al. (1994) prove that in a private values framework, making the reserve price public always yields the seller higher revenue than when it is secret. However, Elyakime et al. (1994) do not incorporate the effect of endogenous entry in their results. It is also conceivable that in a common value setting, a different conclusion might arise. Although we do not know of any general result concerning the benefits/costs of using secret reserve prices, the structural model that we build in the sections 4 and 5 allows us to simulate the effects of different reserve price policies on seller revenues.

\subsection{Revenues, profit margins and values}

The summary statistics in Table 1 reveal that the average revenue (BID1) in the auctions are lower than the average book value of the object being sold. The average revenue (as a percentage of book value) conditional on sale is $95.8 \%$. Keeping in mind that some auctions did not result in a sale, the unconditional revenue is $81.3 \%$.

In table 6 , we define REVN to be the normalized revenue of the item and regress it on the same set of regressors as in the entry regression. We find that an increase in the number of bidders and in the minimum bid increase the revenue and that reported blemishes decrease revenue. Auction type, seller's negative reputation, the average experience of bidders, and the experience level of the winning bidder are not significant determinants of revenue.

The average profit margin of the bidders (taking the book value as the true value of the item) is $4.2 \%$ (with a standard deviation of $30.1 \%$ ). However, this does not take the shipping and handling costs in to account. As we noted in the data section, we have data on only about a third of the sample on the shipping and handling terms. The average profit margin net of shipping and handling costs on this sub-sample is $-16.2 \%$ (std. $37.3 \%$ ). Using the average shipping and handling cost of $\$ 2.18$ in Table 1 for the entire sample, we find that the net profit margin is $-15.4 \%$ (std. $36.4 \%$ ). However, since the standard deviations are very large and the estimates are highly dependent on our measurement of the book value, these figures should be taken with a great deal of skepticism. ${ }^{17}$

What values do bidders assign on the coins for sale? The revenue regression above gives a biased answer to this question, since revenue is the second highest bid in the auction. Even if we believe a private values framework, in which bids are equal to the valuation, we can not answer general

\footnotetext{
${ }^{16}$ Then why do we see a secret reserve price for a $\$ 4$ auction? We found that all except one of the sub- $\$ 10$ secret reserve price auctions ended in sale. Hence we conclude that the seller held the reserve price low enough to ensure the refund of the $\$ 1$ fee. We also found that two sellers account for most of the sub- $\$ 10$ auctions that were conducted with a secret reserve price. These sellers conducted all of their auctions, some with much higher book values, as secret reserve price auctions.

${ }^{17}$ For example, if we use the median value of the net profit margin as our summary statistic, we get $-1.5 \%$ profit net of shipping and handling .
} 
Table 6: Regression of revenue/bookvalue on auction specific variables

\begin{tabular}{||c||c||c||c||}
\hline \hline REVN & Coef. & Std. Err. & t-stat \\
\hline \hline NBIDDER & .0356 & .0071 & 4.988 \\
\hline \hline MINBID/BOOK & .1833 & .0339 & 5.396 \\
\hline \hline SECRET & .0078 & .0446 & 0.176 \\
\hline \hline BLEMISH & -.1286 & .0493 & -2.605 \\
\hline \hline NEGATIVE & -.0021 & .0080 & -0.267 \\
\hline \hline AVGEXP & -.0004 & .0004 & 1.001 \\
\hline \hline PREWIN1 & -0.0002 & .0003 & -0.570 \\
\hline \hline CONSTANT & .7431 & .0438 & 16.932 \\
\hline$R^{2}$ & 0.3327 & & \\
\hline \multicolumn{2}{|l}{} & &
\end{tabular}

Table 7: Regression of normalized bids on auction specific variables

\begin{tabular}{||c||c||c||c||}
\hline \hline BIDN & Coef. & Std. Err. & t-stat \\
\hline \hline MINBID/BOOK & .44316 & .0239 & 18.434 \\
\hline \hline SECRET & -.0294 & .0185 & -1.584 \\
\hline \hline BLEMISH & -.0956 & .0249 & -3.828 \\
\hline \hline NEGATIVE & -.0047 & .0055 & 0.851 \\
\hline \hline PREWIN & 0.00028 & .00012 & 2.365 \\
\hline \hline CONSTANT & .6214 & .0149 & 41.581 \\
\hline$R^{2}$ & 0.2569 & & \\
\hline
\end{tabular}

questions about the valuation of the objects just by looking at the revenue, since revenue is the second-order statistic of the valuation distribution.

Table 7 is the regression of individual bids (normalized over book value) on the regressors in Table 4. We see that once again the minimum bid enters as a significant determinant of overall bids. A reported blemish in the item reduces the bids by $10 \%$. Bidder experience also enters as a weak, but significant factor in determining bid levels.

A straightforward but misleading conclusion from the regressions in Table 6 and Table 7 is to say that revenue and bids increase with the minimum bid. It is easy to see why the conclusion is misleading for the regression table 6: the bids in this regression are observed conditional on the fact that they exceed the minimum bid. Hence, the coefficient on MINBID is subject to selection bias because only bidders with a high willingness to pay for the object will choose to participate in the auction. While the results of this regression are suggestive, we will need to build a structural model in order to consistently estimate the relationship between the reserve price and the bids submitted in the auction. 


\subsection{Bidder experience}

A breakdown of bidder experience measured by number of auctions previously won at eBay reveals a very heterogeneous bidder population (ranging from first time participants to a bidder who has won 557 auctions) with the median bidder having 21 previous wins. However, as was noted in the last section, neither the average experience level of the bidders in an auction, nor the experience of the winning bidder seem to have a significant effect on the revenue of the seller. Also, as seen on Table 5, experience actually has a very weak positive effect on individual bids, i.e. experienced bidders tend to bid higher than inexperienced bidders.

These results point out that despite the heterogeneity of the bidder population, informational asymmetries or differing degrees of bidder sophistication are not likely to be significant issues in this setting. Therefore we will refrain from incorporating ex-ante informational asymmetries in our model.

\section{A model of bidding in eBay coin auctions}

In this section, we develop a model of bidding in eBay coin auctions that we believe captures the main findings of last section and that will allow us to further our ability to understand observed bidding behavior. In the next section, we embed this model in an econometric procedure to estimate its exogenous parameters. This requires that we impose structure onto the bidding process. We understand that it is difficult for a theoretical model to capture the complexity and idiosyncracy of actual bidder behavior. However, the imposed structure is necessary to answer the following questions without ambiguity:

1. What is the informational environment that rationalizes observed bidder behavior? We suggested in the previous section that there is evidence against a private values framework; however, even in a common values framework, we still need to answer the following questions: What does the common value depend on? How diffuse are the bidders' information? It is very difficult to interpret the regression results in the previous section to get good answers to these questions, since the data suffers from both an endogeneity bias due to the endogenous nature of entry, and a truncation due to the minimum bid level. What is needed is a specification that accounts for the fact that entry is endogenous, and that some potential bids are unobserved due to the minimum bid.

2. Another question of use to users of eBay that emerged in the previous section is the following: How does the choice of a minimum bid and/or a secret reserve price affect the revenues of a seller? Although our results in section 3.2 seem to indicate that, at least beyond a certain book value, a secret reserve price auction might be more advantageous to the seller, we also pointed out that there is no known theoretical justification for why this should be true. Our 
structural estimates allow us to simulate the revenue effects using a secret reserve over a public reserve price and to answer this question unambiguously.

Our model assumptions are based on the empirical findings from the previous sections. Hence our model includes a common value element. We also account for the fact that the number of bidders in an auction is a random variable whose realization depends strongly on auction specific observables, most importantly, the minimum bid level. In doing so, we assume that the bidders are ex-ante symmetric, as bidder experience was not found to be a significant determinant of bidding behavior.

In what follows, we first specify a stochastic entry process motivated by the regression in Table 3. We then focus on the bidding game conditional on entry. We argue that the eBay auction, despite its ascending nature, differs significantly from the ascending auction models investigated in the theoretical literature. Instead of capturing the full dynamic nature of the game, we point out that there exists no symmetric equilibrium of the game in which the observable actions of bidders can fully reveal their private information. Moreover, we demonstrate that there exists a symmetric equilibrium in which bidders choose to reveal no information at all, i.e. they all wait until the very end of the auction ${ }^{18}$. In this equilibrium, bids can be modeled as coming from a sealed-bid second price auction, for which the well-known results of Milgrom and Weber (1982) apply. Our equilibrium analysis also incorporates the stochastic nature of the entry process.

\subsection{Model primitives}

We assume that the number of bidders in auction $t$ is a Poisson random variable, with rate $\lambda_{t}$, which depends on the regressors in Table 3. The Poisson random variable arises as the limiting distribution of a sum of independent Bernoulli random variables, each with small probability of success. Since there are millions of users on eBay and thousands of coin collectors browsing auction listings everyday, of which only a few decide to bid in a given auction, we believe the Poisson specification is appropriate in this setting.

We assume that bidders are risk neutral expected utility maximizers. We eschew any dynamic considerations that bidders might have and assume that they focus entirely on the auction at hand ${ }^{19}$. To model the information structure, we assume the symmetric common value setting of Wilson (1977). That is, there is an unknown common value, $v$ of the coin being auctioned, which is distributed according to $f_{v}(v)$ over the support $[\underline{\mathrm{v}}, \bar{v}]$. Since the collectible coins market is characterized by frequent buying and selling, $v$ can represent the unknown resale value of the item. We assume that the prior belief about the distribution of the common value is shared by all bidders.

\footnotetext{
${ }^{18}$ This mode of bidding is also called "sniping." It is interesting to note that there exist shareware programs downloadable from the Web to facilitate such last-minute bids.

${ }^{19}$ We also recognize, but do not model the fact that on eBay similar objects are often being sold side-by-side and that someone in the market for a certain coin can "smooth" her strategies across different auctions.
} 
Given the particular realization of the common value, which is unobserved, bidder $i$ receives a signal $x_{i}$ which is distributed according to $f_{x}\left(x_{i} \mid v\right)$ over the support $[\underline{\mathrm{x}}, \bar{x}]$. We assume that conditional on $v, x_{i}$ are identically and independently distributed and the distribution of bidder signals is common knowledge to all bidders. ${ }^{20}$ We also assume that $f_{x}\left(x_{i} \mid v\right)$ satisfies the monotone likelihood ratio property of Milgrom and Weber (1982) and hence the signals are affiliated ${ }^{21}$.

\subsection{Bidding}

\subsubsection{Auction format}

eBay uses an open ascending auction format. However, the exact format does not fit neatly under the category of "open-exit English auctions" studied by Milgrom and Weber (1982), in which the auctioneer raises the price of the object until all but one of the bidders has dropped out. A bidder can not rejoin the auction once she has dropped out. The key to the analysis in Milgrom and Weber (1982) is that the drop-out decision of a particular bidder conveys information to other bidders, who will update their estimate of the item's true worth and will change their drop-out points. Hence bidding strategy in this type of an ascending auction differs from that in a sealed-bid auction.

However, in eBay agents have the opportunity to update their bids and rejoin the race anytime before the auction ends. With the option to revise one's bid, bidders might not be able to infer others' valuations by observing their drop-out decisions, since "drop-outs" can be insincere. In fact, we will show that there is a Nash equilibrium in which the eBay auction is equivalent to a sealed-bid second-price auction.

To make the above argument more formal, let us view the eBay auction as a two stage auction. Taking the total auction time to be $T$, the first stage auction is an open-exit ascending auction played until $T-\varepsilon$, where $\varepsilon \ll T^{22}$. The drop-out points in this auction are openly observed by all bidders, who will be ordered by their drop-out points in the initial auction, $\theta_{1} \leq \theta_{2} \leq \ldots \leq \theta_{n}$, with only $\theta_{n}$ unobservable (bidders can only infer that it is higher than $\theta_{n-1}$ ). The second stage of the auction transpires from $T-\varepsilon$ to $T$, and is conducted as a sealed bid second price auction in which every bidder, including those who dropped out in the first stage, are given the option to submit a bid, $b$. The highest bidder in the second stage auction wins the object.

This model of the eBay auction captures the ability of bidders to revise their bids. It also is consistent with the empirical finding that quite a few final bids are submitted within the last minutes of the auction. As our experience as bidders on eBay show, the last minutes of the auction

\footnotetext{
${ }^{20}$ Observe that this specification of the common value environment is entirely analogous to that in Section 3.1.

${ }^{21}$ Briefly, affiliation implies that if $v^{\prime}>v$ and $x_{i}>x_{j}$, then $f_{x}\left(x_{i} \mid v^{\prime}\right) f_{x}\left(x_{j} \mid v\right)>f_{x}\left(x_{i} \mid v\right) f_{x}\left(x_{j} \mid v^{\prime}\right)$. Roughly, this means that signals are positively correlated: a high signal for a bidder makes high values for other bidders' signals more likely.

${ }^{22} \varepsilon$ is the time frame in which bidders on Ebay can not update their bids in response to others. This can be on the order of 5-10 minutes, or even longer; as one of the authors had the unpleasant experience of receiving the notification that he was outbid about 2 days after an auction closed.
} 
do resemble a sealed bid auction more than an ascending auction, since delays in e-mail transmission and on the eBay server may make it difficult to follow the bidding in real time ${ }^{23}$.

Given the above setup, we make the following claim:

Proposition 1 The first stage drop-out points $\theta_{i}, i=1, \ldots, n$ can not be of the form $\theta\left(x_{i}\right)$, a monotonic function in bidder $i$ 's signal.

Proof 1 Suppose $\theta_{i}=\theta\left(x_{i}\right)$ a monotonic function in $x_{i}$. Then, since $\theta($.$) is invertible, at the$ beginning of the second stage of the auction, the signals of bidders $i=1, . ., n-1$ become common knowledge. Then, the second stage bid functions will be the expected value of the object given the information available to the bidders ${ }^{24}$ :

$$
\begin{aligned}
b_{i \neq n} & =\max \left\{\theta_{i}, E\left[v \mid x_{1}=\theta^{-1}\left(\theta_{1}\right), \ldots, x_{n-1}=\theta^{-1}\left(\theta_{n-1}\right), x_{n} \geq \theta^{-1}\left(\theta_{n-1}\right)\right\}\right. \\
b_{n} & =\max \left\{\theta_{n}, E\left[v \mid x_{1}=\theta^{-1}\left(\theta_{1}\right), \ldots, x_{n-1}=\theta^{-1}\left(\theta_{n-1}\right), x_{n}=x_{n}\right\}\right.
\end{aligned}
$$

Observe that this results in identical bids for bidders $i \neq n$, provided that their signals are high enough, since they all form the same expectation of the common value. The expectation formed by the highest bidder in the first stage is a little different, since she knows her own value with certainty.

In this situation, there is a profitable deviation. If bidder $j$ decreases her drop-out point in the first stage to $\hat{\theta}_{j}<\theta_{j}$, then in the second stage

$$
b_{i \neq j}\left(\hat{\theta}_{j}\right) \leq b_{i \neq j}\left(\theta_{j}\right)
$$

since the conditional expectations are decreasing in $\theta_{j}$ by Milgrom and Weber (1982) 's Theorem 5. But since all other bidders are bidding sincerely in the first stage, $j$ 's bid will not change, and she will unilaterally increase her probability of winning the auction.

If the bidders can not bid sincerely in the first stage of the auction, then the ascending auction aspect of eBay leads to less information revelation than in the models of ascending auctions in Milgrom and Weber (1982), Wilson (1995) and the structural econometric model of Hong and Shum (1997). In fact, the following result reveals that the eBay auction format might not have any advantages over a sealed bid second price auction:

Proposition 2 Bidding 0 (or not bidding at all) in the first stage of the auction and participating only in the second stage of the auction is a symmetric Nash equilibrium of the eBay auction. In this case the eBay auction is equivalent to a sealed bid second price auction.

\footnotetext{
${ }^{23}$ Visitors to eBay can attest to the fact that navigation can be quite slow at times.

${ }^{24}$ Since bidders are risk neutral, this follows from exactly the same argument behind sincere bidding in private value second price auctions: if, given the information available, I bid higher than my conditional expectation of the value of the item, then on average, I make a loss. If, on the other hand, I bid lower than my conditional expectation, then I lower the probability I will win, but since my payment does not change (since it is the bid of the second highest bidder), my expected profit is lower.
} 
Proof 2 Bidding 0 in the first stage reveals nothing about a bidder's signal in the first stage. Therefore the second stage is just a sealed bid second price auction, where each bidder knows only her own signal. In this case, the symmetric equilibrium bid function, as derived by Milgrom and Weber (1982), is $b(x)=v(x, x)$, where $v(x, y)=E\left[v \mid x_{i}=x, y_{i}=y\right]$, with $y_{i}=\max _{j \in\{1, \ldots, n\} \backslash i}\left\{x_{j}\right\}$. To rule out profitable deviations, observe the following: if bidder $j$ were to bid $\theta_{j}>0$, then it would be evident that $x_{j}>0$, and since signals are affiliated, $E\left[v \mid x_{i}=x, y_{i}=x, x_{j}>0\right] \geq E\left[v \mid x_{i}=x, y_{i}=x\right]$, so bidder $j$ would unilaterally decrease her probability of winning ${ }^{25}$.

The main drawback of the above analysis is that our data reveals that bidders on eBay do not necessarily follow this equilibrium. This is not very surprising, because aside from this one symmetric equilibrium, there might exist many asymmetric equilibria. However, the main point of our logic is clear: there is no symmetric equilibrium of the eBay auction where bidders can learn much from the drop-out decisions of others. Therefore if we are going to focus on symmetric equilibria in our econometric evaluation, we have no choice but to model the bids as if they were submitted in a sealed-bid auction.

As an interesting aside, we should note that one of the main competitors of eBay, Amazon's auction site, extends its auctions beyond the prespecified closing time until bidding activity $\operatorname{ceases}^{26}$. This feature changes the analysis above, since the "sealed-bid second-stage" of the auction no longer exists ( $T$ is no longer set, so bidders can not coordinate on the "blind-bidding" period $[T-\varepsilon, T]$ ). In this case, "drop-outs" are final, since the end of the auction is dependent on bidder activity. The open-exit ascending auction framework of Milgrom and Weber (1982) can be applied here. Moreover, under the assumption of affiliated signals, it can be shown that the Amazon auction results in higher expected revenue to the seller than in the symmetric equilibrium of the eBay auction analyzed above ${ }^{27}$. Hence Amazon has a more "seller-friendly" mechanism than eBay.

There are other reasons why auction sites might introduce features like this to prevent the type of "sniping" we observe on eBay. First of all, it would be very difficult to regulate transactions traffic on the Web server if all bids were to come in at the last few minutes of the auction. This would cause higher congestion and more frequent service outages, driving customers away. Also, sniping could discourage occasional bidders from entering the auction, since they might not find it worthwhile to wait patiently until the very end of an auction.

So why does eBay stick with its hard-deadline policy? One reason could simply be resistance to change: since quite a few customers have invested time into deciphering eBay's system, they might protest attempts to change the auction mechanism (which was quite recently the case, when eBay tried, unsuccessfully, to modify its reserve price rules). Another is that hard-deadlines maybe seen

\footnotetext{
${ }^{25}$ In fact, we can generalize the above equilibrium to a continuum of "symmetric pooling equilibria" where bidders with signal $x \geq x^{*}$ bid $\theta^{*}$ in the first stage. However, this cutoff point is very difficult to coordinate on, and zero seems to be the most likely focal point for such symmetric equilibria.

${ }^{26}$ More precisely, the auction duration is extended until there are no more bids within a 10 minute period.

${ }^{27}$ The revenue comparison is between an English auction and a sealed-bid second price auction. See Milgrom and Weber (1982), Theorem 11.
} 
beneficial by bidders and sellers with time constraints, in that they prevent auctions from dragging on. Yet eBay does try to convince bidders that "sniping" is not a strategy they should use. As we mentioned above, eBay's bidding tutorial assumes a private values framework and explains that with private values, the dominant strategy is to bid one's valuation and sit back.

\subsubsection{Bidding in a sealed bid second price auction with a random number of bidders:}

Since we are using a sealed bid second price auction as our model of bidding conditional upon entry, we will develop the bidding strategies in this auction format. If the number of bidders is common knowledge, then the bid function derived by Milgrom and Weber (1982) applies (recall that $\left.y_{i}=\max _{j \in\{1, \ldots, n\} \backslash i}\left\{x_{j}\right\}\right)$ :

$$
\begin{aligned}
b(x) & =E\left[v \mid x_{i}=x, y_{i}=y\right] \\
& =\frac{\int_{\underline{v}}^{\bar{v}} v f_{x}^{2}(x \mid v) F_{x}^{n-2}(x \mid v) f_{v}(v) d v}{\int_{\underline{\mathbf{v}}}^{\bar{v}} f_{x}^{2}(x \mid v) F_{x}^{n-2}(x \mid v) f_{v}(v) d v}
\end{aligned}
$$

where $f_{v}(v)$ is the density function of the common value and $f_{x}(x \mid v)$ and $F_{x}(x \mid v)$ are the conditional density and distribution functions of the signal.

However, as we noted in the section on entry, the number of bidders is not common knowledge on eBay. The best we can hope for is that bidders have rational expectations about the number of competitors they are going to face. Therefore we have to introduce this uncertainty into our model of bidding.

Proposition 3 Let $p(n, \lambda)$ be the pdf of the number of bidders in the auction conditional upon entry of particular bidder to the auction. Also define $y_{i}^{(n)}=\max _{j \in\{1, \ldots, n\} \backslash i}\left\{x_{j}\right\}$ and $v(x, y, n)=E\left[v \mid x_{i}=\right.$ $\left.x, y_{i}^{(n)}=y\right]$. Then if the function

$$
b^{*}(x, \lambda)=\frac{\sum_{n=2}^{\bar{N}} v(x, x, n) f_{y_{i}^{(n)}}(x \mid x) p(n, \lambda)}{\sum_{n=2}^{\bar{N}} f_{y_{i}^{(n)}}(x \mid x) p(n, \lambda)}
$$

is increasing in $x$, then it is a symmetric Nash equilibrium of the common value second price auction game with a random number of bidders.

Proof 3 See Appendix A.

As can be seen by inspection, the bid function in the case of stochastic bidders is a weighted average of bid functions with a given number of bidders, where the weighting factor is $\frac{f_{y_{i}(n)}(x \mid x) p(n, \lambda)}{\sum_{n=2}^{N} f_{y_{i}(n)}(x \mid x) p(n, \lambda)}$. So, once the bid functions in the deterministic case are solved for, we can easily compute the bid function in the stochastic case, using $p(n, \lambda)$. 


\subsubsection{Properties of the bid function}

Although we have the bid function in closed form, to analyze its properties and to use it in a computational procedure, we still have to evaluate the integrals in the numerator and denominator numerically. Fortunately, if we assume that $v \sim N\left(\mu, \sigma_{v}^{2}\right)$ and $x \mid v \sim N\left(v, k \sigma_{v}^{2}\right)$, we can compute this bid function with very high accuracy using the Gauss-Hermite quadrature method (see Judd (1998) and Stroud and Secrest (1968) for details).

Figure 2 plots the bid functions in an auction where are $\mu=1, \sigma=0.6$ and $k=0.3$. We see that the functions look quite linear (with a slope of about 0.85) and are indeed increasing in $x$. More interestingly, these plots also show that bids are also decreasing in $\lambda$, the expected number of bidders in the auction. So the "winner's curse" does increase with the number of competitors.

The apparent linearity of the bid functions might raise questions about the validity of the computational procedure or whether there is a theoretical result remaining to be proved about the behavior of bid functions under the distributional we have made. To answer the first question, we have repeated our calculations for an increasing number of quadrature points, and, instead of using the Gauss-Hermite quadrature evaluation points, have also tried simulating the integrals. Both methods gave similar results. As to whether it can theoretically be shown whether the bid functions are linear, we have only been able to verify that linearity holds only in the (deterministic number of bidders) case when $n=2$. In this case, the bid function is:

$$
\begin{aligned}
v(x, x) & =E\left[v \mid x_{1}=x, x_{2}=x\right] \\
& =\frac{k \mu+2 x}{2+k}
\end{aligned}
$$

It could be conjectured, then, that as the number of bidders gets larger, the departure from linearity remains slight.

Another "linearity" property that we did succeed in verifying theoretically is that bid functions scale linearly when the signal distribution undergoes a linear transformation. That is:

Proposition 4 Let $b\left(x \mid \mu^{o}, \sigma^{o}, k, \lambda\right)$ be the bid function in an auction where the common value $v$ is distributed normally with mean $\mu^{o}$ and standard deviation $\sigma^{\circ}$. We claim that in an auction where the common value is distributed with mean $r_{1} \mu^{o}+r_{2}$ and standard deviation $r_{1} \sigma^{o}$, the equilibrium bid function is $r_{1} b\left(r_{1} x+r_{2} \mid \mu^{o}, \sigma^{o}, k, \lambda\right)+r_{2}$. That is, if it was optimal to bid $b$ with a signal $x$ in the original auction with the common value distributed $N\left(\mu^{o}, \sigma^{o}\right)$, it is now optimal to bid $r_{1} b+r_{2}$ when your signal is $r_{1} x+r_{2}$, with the common value distributed $N\left(r_{1} \mu^{o}+r_{2}, r_{1} \sigma^{o}\right)$.

Proof 4 See Appendix A.

Observe that the above argument depends only on the linearity of the expectation of the common value given other bidder's signals, and the existence of monotonic bid functions. Therefore, we can 
extend this result to any auction where bidder signals are distributed according to a location-scale family, and where the common value or the expectation of the common value is a linear function of the bidders' signals.

This is a key result in our estimation procedure, because it allows us to compute the bid function only once for a base-case auction. We can then apply an affine transformation to this "pre-computed" function to find the bid function in an auction where the distribution of the common value has a different mean and variance.

It is worthwhile to note that bid functions will be likewise linearly scalable in many commonly studied auctions, such as the first price sealed bid auction. Elyakime et al. (1994) note that efficient evalution of the bid function is a key problem in structural estimation of auction models. The simplification we propose can be used to for structural estimation in a wide variety of models where the bid function is linearly scalable and the distribution of valuations is characterized by its first two moments.

\subsubsection{Minimum bids}

eBay allows the seller to set a minimum bid. Since minimum bids induce truncation on the set of bids (and hence valuations) we observe, it is necessary to incorporate the truncation region in our likelihood function.

However, in the case of a minimum bid $r$, equilibrium strategies are derived by Milgrom and Weber to be:

$$
\begin{array}{ll}
b(x)=v(x, x) & \text { for } \quad x \geq x^{*} \\
b(x)<r & \text { for } x<x^{* 28}
\end{array}
$$

where $x^{*}=x^{*}(r)$ is called the screening level and is given by

$$
x^{*}(r)=\inf \left\{E\left[v \mid x_{i}=x, y_{i}<x\right] \geq r\right\}
$$

Since the above expectation is monotonic in $v$ (due to affiliation), the screening level is the solution of:

$$
\frac{\int_{\mathrm{v}}^{v} v f_{x}^{2}\left(x^{*} \mid v\right) F_{x}^{n-1}\left(x^{*} \mid v\right) f_{v}(v) d v}{\int_{\mathrm{v}}^{v} f_{x}^{2}\left(x^{*} \mid v\right) F_{x}^{n-1}\left(x^{*} \mid v\right) f_{v}(v) d v}=r
$$

We calculate $x^{*}$ for a string of values of $r$ and use interpolation to find $x^{*}$ in our likelihood function evaluations.

For the case of a stochastic number of bidders, the above equilibrium generalizes to: 


$$
\begin{aligned}
& b(x, \lambda)=\frac{\sum_{n=2}^{\bar{N}} v(x, x, n) f_{y_{i}^{(n)}}(x \mid x) p(n, \lambda)}{\sum_{n=2}^{\bar{N}} f_{y_{i}^{(n)}}(x \mid x) p(n, \lambda)} \text { for } \quad x \geq x^{*} \\
& b(x, \lambda)=0 \quad \text { for } x<x^{*}
\end{aligned}
$$

where $x^{*}$ is the expected screening level

$$
x^{*}(r, \lambda)=\inf \left\{E_{N} E\left[v \mid x_{i}=x, x_{i}<x, N=n\right] \geq r\right\}
$$

which can be calculated as the solution of:

$$
p(1, \lambda) E[v \mid x]+\sum_{n=2}^{\bar{N}} p(n, \lambda) \frac{\int_{\mathrm{v}}^{v} v f_{x}^{2}\left(x^{*} \mid v\right) F_{x}^{n-1}\left(x^{*} \mid v\right) f_{v}(v) d v}{\int_{\mathrm{v}}^{v} f_{x}^{2}\left(x^{*} \mid v\right) F_{x}^{n-1}\left(x^{*} \mid v\right) f_{v}(v) d v}=r
$$

Once again, normality assumptions allow us to compute the integrals in the above expressions with very high accuracy using the Gaussian quadrature method. However, we also need to solve for $x^{*}$ in expression (3) using a numerical procedure. We use a simple Newton-Raphson algorithm to find this solution.

Figure 3 plots the screening level as a function of the minimum bid for the auction with $\mu=$ $1, \sigma=0.6$ and $k=0.3$. The screening level appears to depend on the minimum bid in a similar

near-linear fashion. From the two cases, $\lambda=3$ and $\lambda=5$, that are plotted in this figure, we also see that the screening level is decreasing in $\lambda$ and, as shown by Milgrom and Weber (1982), is above the minimum bid.

\subsubsection{Secret Reserve Prices}

We will use a shortcut in modelling the effect of a secret reserve price on bidding behavior: we will assume that bidders believe that the seller's valuation for the item comes from the same information structure as theirs, i.e. the seller is yet another bidder. This makes sense if the seller has good enough outside options, i.e. she's not constrained to sell the item immediately, or on eBay. Since quite a few sellers on eBay are professional coin traders, this condition is likely to be satisfied.

With this assumption, the only difference between the secret reserve price auction and a regular auction is that now potential bidders know that they face at least one competitor, the seller, so now:

$$
b^{S R}(x, \lambda)=\frac{\sum_{n=2}^{\bar{N}} v(x, x, n) f_{y_{i}^{(n)}}(x \mid x) p(n-1, \lambda)}{\sum_{n=2}^{\bar{N}} f_{y_{i}^{(n)}}(x \mid x) p(n-1, \lambda)}
$$

A minimum bid is similarly incorporated into the secret reserve price setting. The screening level, $x^{* S R}(r, \lambda)$ in this case is the solution of: 


$$
\sum_{n=2}^{\bar{N}} p(n-1, \lambda) \frac{\int_{\mathrm{v}}^{v} v f_{x}^{2}\left(x^{*} \mid v\right) F_{x}^{n-1}\left(x^{*} \mid v\right) f_{v}(v) d v}{\int_{\mathrm{v}}^{v} f_{x}^{2}\left(x^{*} \mid v\right) F_{x}^{n-1}\left(x^{*} \mid v\right) f_{v}(v) d v}=r
$$

\section{Structural Estimation of the Model}

In order to make predictions using the above model, we need to compute the bid functions for a set of "reasonable" parameter values. The problem is that the "structural parameters" of our model, i.e. the parameters of the prior density of the common value $f_{v}(v)$ and the conditional density of bidders' signals, $f_{x}(x \mid v)$, are not observable from data. The next section outlines a structural estimation method to uncover these unobservables from data.

\subsection{Specification of the information structure and entry process}

We will assume that the prior distribution on the common value and the conditional distributions of bidders' signals are normally distributed. The normality assumption is motivated not only by its computational convenience, but also from an inspection of the bid distribution (normalized by book value) in Figure 4, which resembles a normal distribution fairly well. We specify the prior distribution of the common value in auction $t$ to be $N\left(\mu_{t}, \sigma_{t}^{2}\right)$, where:

$$
\begin{aligned}
\mu_{t}= & \mu_{t}\left(\beta, B O O K V A L_{t}, B L E M I S H_{t}\right) \\
= & \beta_{1} \text { BOOKVAL } L_{t}+\beta_{2} B L E M I S H_{t} B O O K V A L_{t}-2.18 \\
\sigma_{t} & =\sigma_{t}\left(\beta, B O O K V A L_{t}, B L E M I S H_{t}\right) \\
& =\beta_{3} \text { BOOKVAL }+\beta_{4} B L E M I S H_{t} B O O K V A L_{t}
\end{aligned}
$$

This choice for modeling the common value is motivated in part by our reduced form finds that objects with a blemish are sold at a discount in the auction. Also, since agents must pay shipping and handling fees, we subtract $\$ 2.18$ in computing $\mu_{t}$, the average shipping and handling fee for the mint/proof sets ${ }^{29}$. The parameter vector $\beta=\left(\beta_{1}, \beta_{2}, \beta_{3}, \beta_{4}\right)$ is held constant across all auctions and all bidders so that identification of these parameters is possible.

The distribution of individual signals conditional on the common value is $N\left(v_{t}, k \sigma_{t}^{2}\right)$ where $k=\beta_{5}$ is a parameter to be estimated. This parameter models the uncertainty in the private signals. In the case where $k=0$, we have the private values situation. We hold $k$ constant across auctions for identification.

\footnotetext{
${ }^{29}$ Our data on shipping and handling has a lot of missing values, so we chose not to use the individual values.
} 
We use a reduced form specification for $\lambda_{t}$, the Poisson parameter for entry, motivated by the regression in Table 3. In order to avoid negative values of $\lambda_{t}$, we use its $\log$ as the dependent variable:

$$
\begin{aligned}
\log \lambda_{t}= & \beta_{6}+\beta_{7} S E C R E T_{t}+\beta_{8} L N\left(B_{O O O K_{t}}\right)+\beta_{9} N E G A T I V E_{t} \\
& +\beta_{10} S E C R E T_{t} \frac{M I N B I D_{t}}{B O O K V A L_{t}}+\beta_{11}(1-S E C R E T) \frac{M I N B I D_{t}}{B O O K V A L_{t}}
\end{aligned}
$$

\subsection{Likelihood function}

The equilibrium bid functions we derived in the previous sections generate a likelihood function in a natural way. Let $\Omega_{t}$ be shorthand for $\left\{\lambda_{t}, S E C R E T_{t}, r_{t}\right\}$; the Poisson parameter for auction $t$, the auction type, and, the minimum bid. Then $b\left(x \mid v, \sigma_{t}, k, \Omega_{t}\right)$ denotes the equilibrium bid function given a particular (unobserved) realization of the common value, the variance of the conditional distribution of the bidder's signal and the information contained in $\Omega_{t}$.

Assuming that the bids in our dataset are generated by equilibrium bidding, we can calculate the distribution of the unobserved signals given the observed distribution of bids. Let $\phi\left(b \mid v, \sigma_{t}, k, \Omega_{t}\right)$ denote the inverse bid function, mapping the observed bid to the unobserved individual signal $x$. Then $f_{b}\left(b_{i} \mid v, \sigma_{t}, k, \Omega_{t}\right)$, the probability that player $i$ submits a bid $b_{i}$ in auction $t$ is:

$$
f_{b}\left(b_{i} \mid v, \sigma_{t}, k, \Omega_{t}\right)=f_{x}\left(\phi\left(b_{i} \mid v, \sigma_{t}, k, \Omega_{t}\right)\right) \phi^{\prime}\left(b_{i} \mid v, \sigma_{t}, k, \Omega_{t}\right)
$$

Unfortunately, neither the inverse bid function $\phi($.$) nor its derivative \phi^{\prime}($.$) are available in closed$ form for the auctions we consider. In Appendix B, we outline a computational procedure to evaluate $\phi\left(b_{i} \mid v, \sigma_{t}, k, \Omega_{t}\right), \phi^{\prime}\left(b_{i} \mid v, \sigma_{t}, k, \Omega_{t}\right)$ efficiently.

To find the likelihood for the observed bids $b=\left(b_{1}, \ldots, b_{n_{t}}\right)$ it is necessary to account for the fact that the $b_{i}$ are correlated through the realization of $v$. Also, remember that for the winning bidder, we do not observe the bid directly, but his payment. Then in an auction where there is no minimum bid, the probability of observing the bids $b=\left(b_{1}, \ldots, b_{n_{t}}\right)$ is:

$$
\begin{aligned}
& f\left(b_{1}, b_{2}, \ldots, b_{n_{t}} \mid \mu_{t}, \sigma_{t}, \Omega_{t}\right) \\
= & p\left(n_{t} \mid \lambda_{t}\right) * \int_{-\infty}^{\infty}\left(1-F_{x}\left(\phi\left(b_{1} \mid v, \sigma_{t}, k, \Omega_{t}\right)\right) *\right. \\
& \prod_{i=2}^{n_{t}} f_{b}\left(b_{i} \mid v, \sigma_{t}, k, \Omega_{t}\right) f\left(v \mid \mu_{t}, \sigma_{t}\right) d v
\end{aligned}
$$

Observe that we also to took into account that $n_{t}$ bidders showed up as a result of a stochastic 
process, by adding in $p\left(n_{t} \mid \lambda_{t}\right)^{30}$.

In an auction with a minimum bid, we have to take into account that some entrants might have drawn signals that are lower than the screening level $x^{*}\left(\lambda_{t}, r_{t}\right)$ and hence have not submitted a bid.

$$
\begin{aligned}
& f\left(b_{1}, b_{2}, \ldots, b_{n} \mid \mu_{t}, \sigma_{t}, \Omega_{t}\right) \\
= & \sum_{j=n_{t}}^{\bar{N}} p\left(j \mid \lambda_{t}\right) * \int_{-\infty}^{\infty}\left\{F _ { x } ( x ^ { * } | v , \sigma _ { t } , k , \Omega _ { t } ) ^ { j - n _ { t } } \left(1-F_{x}\left(\phi\left(b_{1} \mid v, \sigma_{t}, k, \Omega_{t}\right)\right)^{1\left\{n_{t} \geq 1\right\}} *\right.\right. \\
& \left.\prod_{i=2}^{n_{t}} f_{b}\left(b_{i} \mid v, \sigma_{t}, k, \Omega_{t}\right) f\left(v \mid \mu_{t}, \sigma_{t}\right)\right\} d v
\end{aligned}
$$

where $1\left\{n_{t} \geq 1\right\}$ is an indicator variable for at least one bidder in the auction and $\bar{N}$ is an upper bound on the number of entrants. ${ }^{31}$ Observe that this specification allows us to assign positive likelihood to auctions with no bidders.

For auctions with a secret reserve price, the likelihood function in (11) should reflect the fact that bidders assume that seller is another competitor (who is certain to be there) and that they use a different bid function because of this assumption:

$$
\begin{aligned}
& f\left(b_{1}, b_{2}, \ldots, b_{n} \mid \mu_{t}, \sigma_{t}, \Omega_{t}\right) \\
= & \sum_{j=n_{t}}^{\bar{N}} p\left(j \mid \lambda_{t}\right) * \int_{-\infty}^{\infty}\left\{F _ { x } ( x ^ { * S R } | v , \sigma _ { t } , k , \Omega _ { t } ) ^ { j - n _ { t } } \left(1-F_{x}\left(\phi^{S R}\left(b_{1} \mid v, \sigma_{t}, k, \Omega_{t}\right)\right)^{1\left\{n_{t} \geq 1\right\}} *\right.\right. \\
& \left.\prod_{i=2}^{n_{t}} f_{b}\left(b_{i}^{S R} \mid v, \sigma_{t}, k, \Omega_{t}\right) f\left(v \mid \mu_{t}, \sigma_{t}\right)\right\} d v
\end{aligned}
$$

The full likelihood function can then be constructed as follows:

$$
L\left(B I D S_{t} \mid \beta\right)=\prod_{t=1}^{T} f\left(b_{1}, b_{2}, \ldots, b_{n} \mid \mu_{t}, \sigma_{t}, \Omega_{t}\right)
$$

\subsection{Posterior simulation}

Our econometric approach will be Bayesian. As Hendricks and Paarsch (1995) point out, many auction models generate likelihood functions that do not have standard asymptotics and therefore

\footnotetext{
${ }^{30}$ We assume that with a zero reserve price the probability of not bidding conditional upon entering the auction is zero. That is, bidders always draw high enough valuations after they've incurred the bid preparation cost to make bidding worthwhile. Correcting for truncation at zero slows down the computation of the likelihood function, and does not change the results discernibly.

${ }^{31}$ With a Poisson process, $\bar{N}=\infty$. But this makes it impossible to account for the truncation in bids due to the reserve price, hence we take $\bar{N}$ to be a large enough number so that the difference between the truncated Poisson distribution and the full distribution is negligible. We found that $\bar{N}=30$ is good enough for the range of $\lambda^{\prime}$ s we consider.
} 
large sample approaches to inference are difficult to implement econometrically. We will counter the classical objection to the arbitrariness of Bayesian priors with the following: there are over 1000 observed bids in the data set and the likelihood function will therefore have considerably more weight than the prior in forming the posterior.

For the purposes of this analysis we will impose flat priors with bounded support on the vector of parameters $\left\{\beta_{1}, . ., \beta_{10}\right\}$. Let

$$
X_{t}=\left\{S E C R E T_{t}, B O O K V A L_{t}, B L E M I S H_{t}, N E G A T I V E_{t}, M I N B I D_{t}\right\}
$$

be the auction-specific data vector and $p\left(\beta \mid B I D S_{t}, X_{t}\right)$ denote the posterior distribution of the vector of parameters $\beta$ conditional upon the observed data. By Bayes theorem:

$$
p\left(\beta \mid B I D S_{t}, X_{t}\right) \propto p(\beta) L\left(B I D \mid \beta, X_{t}\right)
$$

That is, the posterior is proportional to the prior times the likelihood function. In general, we are interested in moments of $\beta$ or functions of $\beta$; and these can be computed by averaging over the posterior. For example, the expectation of $\beta$ is given by:

$$
\begin{aligned}
E\left[\beta \mid B I D S_{t}, X_{t}\right] & =\int \beta p\left(\beta \mid B I D S_{t}, X_{t}\right) d \beta \\
& =\frac{\int \beta p(\beta) L\left(B I D S_{t} \mid \beta, X_{t}\right) d \beta}{\int p(\beta) L\left(B I D S_{t} \mid \beta, X_{t}\right) d \beta}
\end{aligned}
$$

Unfortunately, the integrals in the numerator and denominator are difficult to evaluate analytically except in a very limited class of conjugate prior/likelihood families. Our likelihood function and priors certainly do not fall within this class. However, recent work in Bayesian econometrics has developed methods to the simulate draws from the posterior distribution, so that the integrals in the numerator and the denominator can be evaluated using Monte-Carlo simulation. In this research we will use a variant of a Metropolis-Hastings algorithm, which is discussed in Geweke (1996). Details of the algorithm are discussed in Appendix C.

\section{Results}

Table 8 reports the results of our simulations of the posterior distribution of $\beta$ for our structural model. All results are from a posterior simulation of 30,000 draws with an initial "burn-in" of 10,000 draws. Convergence to the posterior appeared to be rapid.

These parameter values translate into the following inferences: 
Table 8: Posterior Means and Standard Deviations of Structural Parameters

\begin{tabular}{||l||l||l||l||}
\hline \hline Parameter & Mean & Std. Dev. & p-value \\
\hline \hline$\beta_{1}$ & 0.9911 & 0.0387 & 1.0 \\
\hline \hline$\beta_{2}$ & -0.1446 & 0.1628 & 0.7820 \\
\hline \hline$\beta_{3}$ & 0.5599 & 0.0260 & 1.0 \\
\hline \hline$\beta_{4}$ & 0.0326 & 0.0260 & 0.9402 \\
\hline \hline$\beta_{5}$ & 0.2545 & 0.0259 & 1.0 \\
\hline \hline$\beta_{6}$ & 1.4069 & 0.0897 & 1.0 \\
\hline \hline$\beta_{7}$ & -0.2857 & 0.1080 & 1.0 \\
\hline \hline$\beta_{8}$ & 0.0883 & 0.0276 & 1.0 \\
\hline \hline$\beta_{9}$ & -0.0414 & 0.0228 & 0.9684 \\
\hline \hline$\beta_{10}$ & -0.2514 & 0.3268 & 0.6146 \\
\hline \hline$\beta_{11}$ & -0.7893 & 0.0864 & 1.0 \\
\hline \hline
\end{tabular}

- The information structure: Bidders have a mean valuation that is almost equal to the bookvalue of the item. Reported blemishes do not seem to have a significant effect on this valuation. The standard deviation of the prior distribution on the value of the item is $56 \%$ of the bookvalue. A blemish increases this variance by $3 \%$. However, bidders' signals (conditional on the realization of the common value) are more precise. Since $k=\beta_{5}=0.2545$, the standard deviation of the conditional distribution of bidders' signals is $\sqrt{k} \sigma_{v}=28.25 \%$ of the bookvalue.

- Entry: Given equation (8), the reserve price mechanism, minimum bid level in an ordinary auction and the bookvalue of the coin appear as the main determinants of entry to the auction. Negative seller reputation also reduces entry. The minimum bid level in a secret reserve price auction does not affect the entry decision significantly.

To help interpret our estimates, we'll walk through the decision process of a typical bidder on eBay: a potential bidder will first peruse auction listings for a while, selecting the auction(s) in which she might be willing to participate. She will then read the item description and most likely consult a handy reference like the Official Red Book or Coins magazine to get a sense of the book value of the item. This process, we believe, will take an experienced coin collector no more than a minute or so. As a result the bidder will have formed a "prior" on the distribution of the value of the object. We find that the observed bids can be justified by our model of bidding if this "prior" distribution has a mean that is equal the bookvalue of the item and has a standard deviation that is $56 \%$ of the book value.

We infer from our estimates that published book values do indeed provide point estimates for how the coins are valued on the market ${ }^{33}$. There is, however, considerable uncertainty about the

\footnotetext{
${ }^{33}$ The fact that reported blemishes do not seem to change this valuation significantly stems from the fact that most
} 
value of the coin set about its book value. As we described in the data section, mint/proof sets comprise of uncirculated coins, and any adulteration by the seller would cause the set to lose all its value. Since bidders do not have the opportunity to inspect the items first hand, we believe such an a priori quality uncertainty is plausible ${ }^{34}$.

After the prior is formed in the bidder's mind, she will decide whether to invest the time to submit a bid. This decision will depend on the amount of profit she expects to make, which, in turn depends on the bookvalue of the item, the number of competitors she expects to face, the reputation of the seller and the minimum-bid/reserve price policy set by the seller, as captured by the specification in equation (8). If she decides that it is worth the while to submit a bid in a particular auction, the bidder will enter what we deem a "costly bid preparation" stage. This is the stage where bidders refine their estimate of the value of the coin, by investigating relevant coin prices and market conditions further, and in almost all cases, augmenting any "objective estimate" by introspection. Of course, the amount of effort sunk into preparing a bid will depend on the stakes involved, and is likely to be different for a $\$ 5$ coin and a $\$ 3000$ coin.

We find that the refined estimate of bidders is sharper than the "prior," and the uncertainty about the resale value of the object is reduced to about one third of the book value. Given that bid functions for the estimated parameter values are nearly linear and have a slope of about 0.9, this estimate means that bids within an auction should be dispersed with a standard deviation of about $26 \%$ of book value.

To gauge the degree of fit our model achieves, we simulated the auctions in our data set using our parameter estimates. That is, given the auction specific variables, we generated $n_{t}$ signals for each auction $t$, where $n_{t}$ was generated by the estimated entry process. We then computed the bid functions corresponding to the signals. The top two plots in Figure 5 compares the simulated and actual bid distributions.

Although the mean value of the bid distributions seem to match (the mean for the simulated distribution is $82.7 \%$ of the bookvalue, compared to $83 \%$ for the actual data), Figure 5 tells us that our estimate of the variance of cross-auction heterogeneity ( $\beta_{3}$ in particular) is higher than what seems apparent in the data. The bottom plot in Figure 5 is the simulated distribution of bids when we set $\beta_{3}=0.3$. This seems to match the actual bid distribution better.

In interpreting the above plots, we should bear in mind that looking at Figure 5 alone does not tell anything about within-auction dispersion of bids. However, our empirical specification attempts to match the within-auction dispersion of bids alongside the cross-auction dispersion. Figure 6 is a histogram of the simulated and actual dispersion of bids. We find that the mean dispersion (difference between max and min) of the simulated bids is $23 \%$ of book value. This is lower than the actual

of these "blemishes" were minor details concerning the condition of the container of the coin set, rather than the coins themselves.

${ }^{34}$ In fact, our "profit" figures in section 3.4 only make sense if there is considerable uncertainty about the value of the object about its book value. 
dispersion of bids, which was found to be $32 \%$. Hence we see that in trying to match all moments of the data, our specification has to make a tradeoff between overstating cross-auction heterogeneity and understating within-auction heterogeneity. We believe adding explicit consideration of unobserved heterogeneity into our econometric specification will help achieve a tighter fit; however, such an exercise would greatly complicate the estimation procedure, and is beyond the scope of this paper.

To evaluate our parameter estimates for the entry process, we compare them with the results in Table 3 in section 3.2. The signs of the coefficients on the independent variables seem to be in accord. The difference between the estimates in that regression and parameter estimates for specification (8) is that the dependent variable in Table 3 is the observed number of bidders whereas our structural model specifies the expected number of bidders as the dependent variable. When we predict the expected number of bidders using our estimates, we find that on average 3.3 bidders were expected to show up. Since we allowed for the fact that some bidders may be "screened out" by the minimum bid even after they decide to participate in the auction, it makes sense that the expected number of bidders is higher than the average of the observed number of bidders, which we found to be 3.05.

Using our parameter estimates, we calculated that the expected number of bidders in secret reserve price auctions is, on average, 3.9, as opposed to 3.2 bidders in ordinary auctions. Hence the intuition that secret reserve prices can be used to induce entry is justified. An interesting difference of the parameter results in Table 8 from the results in Table 3 is that entry to secret reserve price auctions is that we find that bidders do react negatively to the existence of a secret reserve price ( $\beta_{7}$ is negative and significant, as opposed to the insignificant coefficient on SECRET in Table 3). This also makes sense from the standpoint of a rational bidder deciding whether to enter an auction: even though ex-ante expected profit may be higher due to the lower minimum bid in secret reserve price auction, there is still a probability that the highest bidder will not win the auction. Hence entry incentives should be curbed somewhat due to the presence of a secret reserve price.

We should point out that our structural estimates of the entry process are driven entirely by bid data; nowhere in the estimation process do we directly impose the condition that the "expected" entry process should resemble the actual entry process. The "fit" of the structural model to the observed entry process could be improved by adding such an auxiliary condition; however, even without imposing this condition we manage to get realistic results.

\subsection{How big is the winner's curse?}

Recall that the measure of the "winner's curse" we used in section 3.1 was the amount a bidder would lower her bid when she believed that there would be an extra bidder in the auction. Plots of the bid function in Figure 2 confirm that, at least within the confines of our modelling framework, bid levels should decline with an increase in expected competition.

To assess the size of the winner's curse in our sample, we computed the bid function in a 
"representative auction" whose characteristics are set at the sample averages reported in Table 1. The bid functions for the "representative auction" and the auction with one extra expected bidder are plotted in Figure 7 . We find that an additional bidder decreases bids by $\$ 1.50$ in this $\$ 47$ auction. In other words, the "winner's curse" reduces bids by $3.2 \%$ for every additional competitor in the auction.

The bid function in the representative auction is once again very close to being linear and has a slope of 0.9 , with an intercept of -0.85 . Therefore, with an estimate at the book value of the object $(\$ 47)$, the bid should be $\$ 41.5$. This is $\$ 5.5$ less than the bid in a private values auction. Hence we see that "common values" plays an important role in the transactions in this market.

To see how reducing the uncertainty about the value of the object affects the bids, we plot the bid function for the case where the standard deviation of $v$ is only $10 \%$ of book value (as opposed to $52 \%$ ). As expected, the bids increase: for an estimate of $\$ 47$, the bid is now $\$ 45$. This is about a $7 \%$ gain! So the seller definitely has an incentive to reduce the uncertainty about the value of the coin set.

\subsection{Cost of entry into an eBay auction}

An interesting exercise we can perform using our parameter estimates is to try to calculate the entry or "bid-preparation" cost that would rationalize the stochastic entry process we observe. Such a cost will be borne by serious bidders who expend time and effort into formulating a good estimate of the value of the coin set and finding a profit maximizing bid. This might be a useful fact to know for sellers trying to prepare description pages for their auctions, as giving adequate information about the object for sale would help reduce this cost and induce entry.

To do this we use the framework developed by Levin and Smith (1994) to analyze auctions with endogeneous entry. In this framework, $n$ out of $N$ bidders decide to enter an auction before they observe their private signal. Contingent on entry, each bidder bears a bid-preparation cost $c$. Levin and Smith (1994) find that there exists a symmetric equilibrium of the endogenous entry game in which each bidder enters the auction with an identical probability $p$. Observe that if this probability is low enough and the number of potential bidders is high enough - conditions likely to be satisfied on eBay - then the Poisson entry process we assumed above is justified.

What is the process through which this entry probability is determined? Levin and Smith (1994) argue that entry will occur until each bidder's ex-ante profit from entering the auction is zero. More specifically, let $V$ be the ex-ante expected value of the item, and $W_{n}$ be the ex-ante expected payment the winning bidder will make to the seller. Then a bidder's expected profit, conditional on entering an auction with $n$ bidders is $\left(V-W_{n}\right) / n-c$, since all bidders are ex-ante symmetric. Define $T_{n}(r)$ to be the probability of trade given $n$ and minimum bid (or reserve price) $r$, and $p_{n}^{i}$ be the probability that there are $n$ bidders in the auction from the perspective of the $i$ th potential bidder, conditional on herself being one of the bidders. Assuming all other bidders are following the 
symmetric entry probability, the following zero-profit condition applies to the $i$ th bidder:

$$
c=\sum_{n=1}^{\infty} \frac{e^{-\lambda} \lambda^{n-1}}{(n-1) !} T_{n}(r) \frac{\left(V-W_{n}\right)}{n}
$$

where, assuming a Poisson approximation, we computed $p_{n}^{i}=\frac{e^{-\lambda} \lambda^{n-1}}{(n-1) !}, n=1, \ldots \infty$.

We can get a feel for the entry cost to the eBay auctions by computing the above expression for the "representative auction" we considered in the previous section. One complication is that $W_{n}$ and $T_{n}(r)$ are ex-ante expected values that are not available in closed form. Therefore we use the following simulation method:

1. Using a Poisson $(\lambda)$ distribution, draw $K$ realizations of $\left\{n_{1}, \ldots, n_{K}\right\}$, the number of bidders in a series of $K$ auctions.

2. Given $n_{k}$, draw $n_{k}$ signals $\left\{x_{1}, \ldots, x_{n_{k}}\right\}$ from the conditional distribution $f(x \mid v)$, whose parameters were estimated previously.

3. Given these signals, compute the bid corresponding to the second highest signal. This will, in the case where the reserve price $r$ is exceeded, give the payment $W_{n}^{(k)}$ for the $k$ th auction in our simulation.

4. Compute the average $\frac{1}{K} \sum \frac{\left(V-W_{n}^{(k)}\right)}{n_{k}}$ to get an estimate for $c$, the cost of entry.

Performing this simulation procedure using 20000 draws, we get that the entry cost implied in the "representative auction" is $\$ 3.20^{35}$. This is about $6.8 \%$ of the bookvalue (\$47) in this auction and it is comparable to the shipping and handling cost.

This "estimate" of the entry cost will change with auction characteristics. However, the entry cost as a percentage of the bookvalue seems very stable. For example, for an auction with bookvalue $\$ 1000$ and a minimum bid of $\$ 600$, the computed entry cost was found to be $\$ 66$, which is $6.6 \%$ of the bookvalue.

A $6-7 \%$ entry cost can be quite significant if the book value of the item is high. Therefore, it might advisable for sellers of high value items to try and reduce this cost by giving out as much information about the item as possible, by providing pictures, certificates of authenticity, or a report from an official coin grading agency like PCGS (Professional Coin Grading Service) ${ }^{36}$.

\subsection{Reserve Price Policy}

\footnotetext{
${ }^{35}$ The number of simulation draws was enough to ensure that the standard deviation of this number was less than 0.05 .

${ }^{36}$ PCGS charges $\$ 30$ for its regular grading service with 21 days of turnaround time.
} 
We can use a similar simulation framework to calculate the expected revenue of the seller under different reserve price policies. As we noted in section 3.2, entry patterns in our data set reveal a benefit of a secret reserve price mechanism over a public reserve price mechanism. The intuition we gave to this benefit was that the seller can induce entry to her auction by setting the minimum bid low, but still manage to extract a higher revenue by keeping her secret reserve price high.

This intuition might not be quite correct given our modelling assumptions for handling the secret reserve price auction. If bidders regard the seller as yet another bidder, then because of the winner's curse effect, they will shade their bids downward to take this extra bidder into account. Hence, regarding expected revenues, the seller trades off this winner's curse effect against the benefit of having more bidders in the auction.

To gauge the validity of this intuition, we run the following simulation exercise: we fix the reserve price at a constant fraction of the book value (we choose this fraction to be $85 \%$, a reasonable guess for a typical secret reserve price). Then for different book values, we simulate both an auction with the minimum bid set at $85 \%$ of book value, and a secret reserve price auction with a minimum bid of zero and secret reserve price at $85 \%$ of book value. In the simulations, we use our parameter estimates for the signal distribution and the entry process, and aside from the book value, we set all other independent variables equal to the sample averages.

Figure 8 reveals that the intuition is correct. For all bookvalues that we considered, expected revenue from a secret reserve price exceeds the revenue from an ordinary auction where the minimum bid is set at the same level as the secret reserve price. Hence we can conclude that the benefit of additional entry outweighs the winner's curse effect.

Figure 9 plots the sale probabilities (as a function of book value) for the two auction formats. The benefit of additional entry into the auction is once again apparent; although bidders might lower their bids to account for the fact that the seller is effectively an extra bidder, inducing more entry by setting a low minimum bid level enhances the probability that a bidder with a high-enough signal will participate.

Looking at Figure 8 , we see that a bookvalue of about $\$ 40$ will amortize the $\$ 1$ cost of registering the auction as a secret reserve price auction. However, the secret reserve price fee is refundable if the auction is successful, so the expected cost of setting a secret reserve price auction is actually about 30 cents. This expected cost is amortized if the bookvalue is about $\$ 10$. So a $\$ 10$ book value emerges as the lower bound to having a secret reserve price auction. Recall that in section 3.2 we found that secret reserve prices are used for higher book value items ${ }^{37}$.

In light of these simulations, our recommendation to the sellers is to use a secret reserve price auction if the item has high enough value, and to set the minimum bid very low to induce entry. As we noted before, this strategy has indeed been discovered by eBay users, and even eBay itself recommends sellers to set a low minimum bid when they are running a secret reserve price auction.

\footnotetext{
${ }^{37}$ Even though we do observe the use of secret reserve price for sub- $\$ 10$, there might be an alternative explanation for this. See footnote 15 in section 3.3.
} 


\section{Conclusion}

In this paper, we have analyzed a data set from eBay coin auctions to investigate the determinants of bidder and seller behavior. Our main empirical findings are the following:

1. The eBay coin auctions that we analyze fit a common values framework better than a private values framework. Observed bidder behavior departs significantly from what would be expected from a private values auction. However, eBay's mechanism design philosophy seems to rely on the private values assumption. Since bidder and seller behavior can vary significantly depending on whether private or common values are at play, we would caution eBay administrators in forming their site and mechanism design policies.

2. Our structural estimation results allowed us to quantify the "winner's curse effect" associated with the existence of common values. We find that the expectation of one additional bidder auction decreases bids by $3.2 \%$ in a representative auction. Also, in this representative auction, bids are $10 \%$ lower than bidders' estimate of the value of the coin set.

3. Entry into an auction seems to play a very important role in determining revenues. The entry patterns we observe seem to be in accord with a setting in which forming an intelligent bid, after observing auction listings, is a costly activity. Hence, bidders enter auctions in which they are likely to be successful. Since a high minimum bid reduces the ex-ante expected profit of a potential bidder, it reduces the incentive to spend time and effort to enter the auction. Hence minimum bids are the most significant determinant of entry into the auction. We also find that higher book value coins attract more bidders, most likely because the dollar value of expected profits increase.

4. Since entry depends crucially on the minimum bid level, one strategy for the seller is to set a low minimum bid and a secret reserve price. Although bidders do account for the fact that there is a secret reserve price, we find that the sellers using this strategy are able to increase entry to an auction and still manage to guarantee a high selling price. We find that for a given reserve price, using the secret reserve price strategy yields the seller higher expected profits. We also find that the secret reserve price strategy should be reserved for higher book value items, since eBay charges a fee to use a secret reserve price.

Along the way, we have also made methodological contributions to the empirical auction literature. For example, to our knowledge, this is the first study in the literature that incorporates the effect of entry explicitly into its econometric specification. By devising an efficient method to compute the bid function for a common value auction, we have also managed to reduce the computational requirements of our estimation procedure. Since this method is easily generalizable to other auction models, we believe future researchers can benefit from our findings when building and estimating parametric structural models of auctions. 
We believe that eBay remains a fertile ground for empirical auction research. For example, we have not explicitly taken into account the "multi-market" nature of eBay, and have treated each auction in isolation. As we mentioned, in the market we studied, very often identical or very similar goods were being sold side-by-side or back-to-back. We have also realized that many sellers have more than one object to sell. Hence eBay provides an ideal testing ground for the exploration of the impact of "temporal" or "spatial" bidder and seller strategies in multi-market settings ${ }^{38}$. Since we also observe significant variation among seller's choices of minimum bids and reserve prices, there is also room to test theories of competition between sellers (Peters and Severinov (1997), McAfee (1993)).

We also believe possible extensions to our work can be made in the setting we have examined. For example, in our structural specification, we have not modeled the sequential nature of entry, and have assumed that the entry decision is made simultaneously. Relaxing this assumption could open the way to dynamic, rather than static, bidding strategies that can be taken to the data. We have also assumed away any consideration of asymmetries between bidders or errors in decision making, although asymmetries and error-prone decision-making can alter the empirical implications of auction models significantly.

\footnotetext{
${ }^{38}$ For example, the per unit shipping and handling costs for a bidder declines if she wins multiple auctions from the same seller. Hence her bidding strategy across different auctions might not completely separable.
} 


\section{A Appendix}

\section{A.1 Proof of proposition 3}

Without loss of generality, focus on the decision of bidder 1 . Suppose the bidders $j \neq i$ adopt strategies $b_{j}=b^{*}\left(x_{j}, \lambda\right)$. Then the highest bid among them, conditional on there being $n$ bidders, will be $W^{(n)}=\max _{2 \leq j \leq n} b_{j}\left(x_{j}\right)$. Since $b^{*}$ is increasing in $x, W^{(n)}=b^{*}\left(y_{1}^{(n)}\right)$ and the expected payoff of bidder 1 from bidding $b$ will be

$$
E_{n}\left[E\left[\left(v-b^{*}\left(y_{1}^{(n)}\right)\right) \chi_{\left\{b^{*}\left(y_{1}^{(n)}\right)<b\right\}} \mid x_{1}=x, n\right]\right]
$$

where $\chi$ is the indicator variable for the event that bidder 1 wins. This is equal to

$$
\begin{aligned}
& E_{n} \int_{\underline{\mathbf{x}}}^{b^{*-1}(b)}\left[v(x, \alpha, n)-b^{*}(\alpha, \lambda)\right] f_{y_{1}^{(n)}}(\alpha \mid x) d \alpha \\
= & \int_{\underline{\mathbf{x}}}^{b^{*-1}(b)}\left\{\sum_{n=2}^{\bar{N}} p(n, \lambda) v(x, \alpha, n) f_{y_{1}^{(n)}}(\alpha \mid x)-b^{*}(\alpha, \lambda) \sum_{n=2}^{\bar{N}} p(n, \lambda) f_{y_{1}^{(n)}}(\alpha \mid x)\right\} d \alpha
\end{aligned}
$$

where

$$
\begin{aligned}
f_{y_{i}^{(n)}}(x \mid x) & =\operatorname{Pr}\left(y_{i}^{(n)}=x \mid x_{i}=x\right) \\
& =\int_{\mathrm{v}}^{v} f_{y_{i}^{(n)}}(x \mid v) f_{v}(v \mid x) d v \\
& =\int_{\mathrm{v}}^{v}(n-1) f_{x}(x \mid v) F_{x}^{n-2}(x \mid v) f_{v}(v \mid x) d v
\end{aligned}
$$

and $f_{v}(v \mid x)$ is the posterior density of the common value given the signal.

The first order condition with respect to $b$ yields:

$$
0=\sum_{n=2}^{\bar{N}} p(n, \lambda) v(x, x, n) f_{y_{1}^{(n)}}(x \mid x)-b^{*}(x, \lambda) \sum_{n=2}^{\bar{N}} p(n, \lambda) f_{y_{1}^{(n)}}(x \mid x)
$$

solving, we get $b^{*}(x, \lambda)$ as above.

\section{A.2 Proof of proposition 4}

The easiest way to see why this should hold true is to look at the von Neumann-Morgenstern (vNM)

utility of a particular bidder $i$ (the payoff given that other bidders submit bids that are monotonic in their signals, $x_{-i}$, and conditional on the number of competitors $n$ ):

$$
\begin{aligned}
u_{i}\left(b_{i}, b_{-i}, x_{i}, x_{-i}, n\right) & =\frac{k \mu+\sum_{j=1}^{n} x_{j}}{n+k}-\max \left\{b_{-i}\left(x_{-i}\right)\right\} \quad \text { if } b_{i}>\max \left\{b_{-i}\left(x_{-i}\right)\right\} \\
& =0 \text { otherwise }
\end{aligned}
$$


The term $\frac{k \mu+\sum_{j=1}^{n} x_{j}}{n+k}$ is the posterior mean of the unknown common value, given all bidders' signals. The objective function that bidder $i$ maximizes is the expectation of the above vNM utility, and the bid he submits is the maximizer.

$$
\begin{aligned}
b_{i} & =\arg \max E_{n} E_{x_{-i}} u_{i}\left(b_{i}, b_{-i}, x_{i}, x_{-i}, n\right) \\
& =\arg \max E_{n} E_{x_{-i} \mid b_{i}>\max \left\{b_{-i}\left(x_{-i}\right)\right\}}\left[\frac{k \mu+x_{i}+\sum_{-i} x_{-i}}{n+k}-\max \left\{b_{-i}\left(x_{-i}\right)\right\}\right]
\end{aligned}
$$

The bid that maximizes bidder $i$ 's expected utility in an auction where the signals are scaled linearly as $r_{1} x+r_{2}$, and where all other bidders follow linearly scaled strategies $r_{1} b_{-i}\left(x_{-i}\right)+r_{2}$ is:

$$
\begin{aligned}
b_{i}^{\prime} & =\arg \max E_{n} E_{r_{1} x_{-i}+r_{2}} u_{i}\left(b_{i}^{\prime}, r_{1} b_{-i}\left(x_{-i}\right)+r_{2}, r_{1} x_{i}+r_{2}, r_{1} x_{-i}+r_{2}, n\right) \\
& =\arg \max E_{n} E_{r_{1} x_{-i}+r_{2} \mid b_{i}^{\prime}>\max \left\{r_{1} b_{-i}\left(x_{-i}\right)+r_{2}\right\}} r_{1}\left[\frac{k \mu+x_{i}+\sum_{-i} x_{-i}}{n+k}-\max \left\{b_{-i}\left(x_{-i}\right)\right\}\right] \\
& =\arg \max E_{n} E_{r_{1} x_{-i}+r_{2} \mid b_{i}^{\prime}>\max \left\{r_{1} b_{-i}\left(x_{-i}\right)+r_{2}\right\}}\left[\frac{k \mu+x_{i}+\sum_{-i} x_{-i}}{n+k}-\max \left\{b_{-i}\left(x_{-i}\right)\right\}\right] \\
& =\arg \max E_{n} E_{x_{-i} \mid \frac{b_{i}^{\prime}-r_{2}}{r_{1}}>\max \left\{b_{-i}\left(x_{-i}\right)\right\}} E\left[\frac{k \mu+x_{i}+\sum_{-i} x_{-i}}{n+k}-\max \left\{b_{-i}\left(x_{-i}\right)\right\}\right]
\end{aligned}
$$

Comparing the last expression with the last line in (15), we see that $\frac{b_{i}^{\prime}-r_{2}}{r_{1}}=b_{i}$, i.e. $b_{i}^{\prime}=r_{1} b_{i}+r_{2}$. Hence the bids follow the same linear transformation that the signals are scaled with.

\section{B Numerical computation of the inverse bid function}

Likelihood function evaluations require that we find the value of the inverse bid function $\phi$ for each bid in auction $t$. Since a closed form expression for the inverse bid function does not exist, this potentially means that we will have to evaluate the bid function $b\left(x \mid \mu_{t}, \sigma_{t}, k, \lambda_{t}\right)$ at least a few times for each bid to find the inverse of $b($.$) using a numerical algorithm like Newton-Raphson. However,$ as we found out while working out the closed forms for equilibrium bid functions, this requires the numerical evaluation of integrals. This is a costly step since we have to evaluate the full-likelihood about 30,000 times in our posterior simulation, and with 1500 bids in the data, the integrals would have to be evaluated at least 45 million times.

To reduce the computational complexity, we first exploit the linearity property of the bid functions. Recall that linearity implies that if $b\left(x \mid \mu^{o}, \sigma^{o}, k, \lambda\right)$ is a pure strategy equilibrium bid function to the auction where the common value is distributed normally with mean $\mu^{o}$ and standard deviation $\sigma^{o}$, then $r_{1} b\left(r_{1} x+r_{2} \mid \mu^{o}, \sigma^{o}, k, \lambda\right)+r_{2}$ is the equilibrium bid function in the auction where the common value is distributed with mean $r_{1} \mu^{o}+r_{2}$ and standard deviation $r_{1} \sigma^{o}$. This result holds regardless of whether there is a known or random number of bidders in the auction. Similarly, if there is a posted reserve price in the auction, we can apply the linear transformation to the screening level $x^{*}(R, \lambda, k)$. That is, if $x^{*}\left(R ; \mu^{o}, \sigma^{o}, \lambda, k\right)$ is the screening level in the original auction, then $r_{1} x^{*}\left(r_{1} R+r ; \mid \mu^{o}, \sigma^{o}, k, \lambda\right)+r_{2}$ will be the screening level in the transformed auction. 
How does linearity help us? Suppose at a particular evaluation of the likelihood function, the distributional parameters are $\left\{\mu_{t}, \sigma_{t}\right\}$ for auction $t$. Then we do not have to evaluate $b\left(x \mid \mu_{t}, \sigma_{t}, k, \lambda\right)$ : setting $r_{1 t}=\frac{\sigma_{t}}{\sigma^{o}}$ and $r_{2 t}=\mu_{t},-r_{1 t} \mu^{o}$, we interpolate the value of $b\left(\frac{x-r_{2 t}}{r_{1 t}} \mid \mu^{o}, \sigma^{o}, k, \lambda\right)$ from a set of pre-computed values, and return $r_{1 t} b\left(\frac{x-r_{2 t}}{r_{1 t}} \mid \mu^{o}, \sigma^{o}, k, \lambda\right)+r_{2 t}{ }^{39}$. Assuming the interpolation is good enough, this scheme lets us avoid computing the Nash equilibrium in the course of likelihood function evaluations. The equilibrium is solved beforehand for a normalized set of parameter values, and adapted to the parameter values generated by the posterior simulation routine.

As for inverting the bid function, one can use a simple algorithm like Newton-Raphson with relative ease, since the bid function is monotonic, and $b(x)=x$ is usually a good starting value. Alternatively, one can evaluate $b\left(x \mid \mu^{o}, \sigma^{o}, k, \lambda\right)$ on the grid used for interpolation, and instead of using polynomial interpolation to find $b$ as a function of $x, k, \lambda$,one can use polynomial interpolation to evaluate $x$ as a function of $b, k, \lambda$. This allows one to approximate the inverse bid function directly, instead of having to evaluate the bid function several times until Newton-Raphson converges. In fact, this method is much more efficient in terms of calculating the derivative of the inverse bid function (the Jacobian), since the derivative of the polynomial interpolation can be written out in closed form, and once again, be evaluated in one step.

\section{Estimation}

\section{C.1 Priors}

Let $p(\beta)$ denote the prior distribution on the parameters. We assume that the prior is proportional to a constant if

$$
\begin{aligned}
0 & <\beta_{1}<3 \\
-2 & <\beta_{2}<2 \\
0 & <\beta_{3}<2 \\
-2 & <\beta_{4}<2 \\
0 & <\beta_{5}<4 \\
0 & <\beta_{6,7,8,9,10}<5
\end{aligned}
$$

and is equal to zero otherwise. We impose these flat priors to minimize the effect of prior choice

\footnotetext{
${ }^{39}$ The computational simplification from linearity can be exploited fully only when we have precomputed values for all possible values of $x, k$ and $\lambda$. Since this is not possible in a computational setting, we precompute the bid function for the "base-case" auction (where the CV is distributed $N\left(\mu^{o}, \sigma^{o}\right)$ ) at a large number grid points $x \in\left\{x_{o}, x_{1}, \ldots, x_{N_{k}}\right\}, k \in\left\{k_{o}, k_{1}, \ldots k_{N_{k}}\right\}, \lambda \in\left\{\lambda_{o}, \ldots, \lambda_{N_{\lambda}}\right\}$ and perform a polynomial interpolation to calculate $b\left(\frac{x-r_{2 t}}{r_{1 t}} \mid \mu^{o}, \sigma^{o}, k, \lambda\right)$ at intermediate values. We took care to restrict the domain of interpolation to a region that is a rather tight cover of the region covered by simulation draws to ensure good performance.
} 
on the shape of the posterior distribution. As for the appropriateness of the cutoff points, we made sure that these contained the "reasonable bounds" for the possible realizations of the parameters.

\section{C.2 Posterior simulation}

In this section we givean outline of the variant of the Metropolis-Hastings algorithm that we used to simulate the posterior distribution of the parameters. The goal of this algorithm is to draw a sequence of random vectors $\beta^{0}, \beta^{1}, \beta^{2} \ldots$ from the posterior distribution. The algorithm starts out by finding a rough approximation to the posterior mode of which we will refer to as $\beta^{\circ}$. Let $H$ be

the Hessian matrix of the posterior distribution at $\beta^{o}$. The algorithm starts with the first element in the sequence as $\beta^{o}$ and is defined inductively as follows:

1. Given $\beta^{n}$ draw a candidate value $\widetilde{\beta}$ from a normal distribution with mean $\beta^{n}$ and variancecovariance matrix $-H^{-1}$.

2. Let

$$
\alpha=\min \left\{\frac{p(\widetilde{\beta} \mid D A T A)}{p\left(\beta^{n} \mid D A T A\right)}, 1\right\}
$$

3. Set $\beta^{n+1}=\widetilde{\beta}$ with probability $\alpha$.

4. Return to 1 .

Intuitively, the algorithm simulates a Markov chain (or a random walk) starting from the posterior mode, which under certain stationarity conditions, converges to an invariant distribution. Geweke (1996)provides sufficient conditions for the invariant distribution of this chain to be the posterior distribution. It is easy to check that these conditions are met in this application. 


\section{References}

Bajari, Patrick, "The First Price Auction with Asymmetric Bidders: Theory and Applications." PhD dissertation, University of Minnesota 1997.

Donald, Stephen G. and Harry J. Paarsch, "Piecewise Pseudo-Maximum Likelihood Estimation in Empirical Models of Auctions," International Economic Review, 1993, 34, 121-148.

Elyakime, Bernard, Jean Jacques Laffont, Patrice Loisel, and Quang Vuong, "First-Price Sealed-Bid Auctions with Secret Reservation Prices," Annales D'Economie Et De Statistique, 1994, 34, 115-141.

Geweke, John, "Posterior Simulators in Econometrics," 1996. University of Minnesota.

Harstad, Ronald M., "Alternative Common Value Auction Procedures: Revenue Comparisons with Free Entry," Journal of Political Economy, 1990, 98, 421-429.

Hendricks, Kenneth and Harry Paarsch, "A Survey of Recent Empirical Work Concerning Auctions," Canadian Journal of Economics, 1995, 28, 403-426.

Hong, Han and Matthew Shum, "The Econometrics of English Auctions," 1997.

Judd, Kenneth, Numerical Methods in Economics, Cambridge, Massachusetts: MIT Press, 1998.

Laffont, Jean Jacques, H. Ossard, and Q. Vuong, "Econometrics of First-Price Auctions," Econometrica, 1995.

Levin, Dan and James L. Smith, "Equilibrium in Auctions with Entry," American Economic Review, 1994, 84, 585-599.

McAfee, R. Preston, "Mechanism design by competing sellers," Econometrica, 1993, 61, 12811312 .

Milgrom, Paul R. and Robert J. Weber, "A Theory of Auctions and Competitive Bidding," Econometrica, 1982, 50, 1089-1122.

Myerson, Roger B., "Optimal Auction Design," Mathematics of Operation Research, 1981, 6, 58-73.

Paarsch, Harry J., "Deciding Between Common Values and Private Vale Paradigms in Empirical Models of Auctions," Journal of Econometrics, 1992, 51, 191-215.

_ _ "Deriving an Estimate of the Optimal Reserve Price: An Application to British Columbian Timber Sales," Journal of Econometrics, 1997, 78, 333-357. 
Peters, Michael and Sergei Severinov, "Competition among sellers who offer auctions instead of prices," Journal of Economic Theory, 1997, 75, 141-179.

Stroud, A. H. and Don Secrest, Gaussian Quadrature Formulas, Englewood Cliffs, New Jersey: Prentice Hall, 1968.

Vickrey, William, "Counterspeculation, Auctions, and Competitive Sealed Tenders," Journal of Finance, 1961, 16, 8-37.

Wilson, Robert, "A Bidding Model of Perfect Competition," Review of Economic Studies, 1977, $44,511-518$.

_ _ , "Sequential Equilibria of Asymmetric Ascending Auctions," Economic Theory, 1995. 
Figure 1:

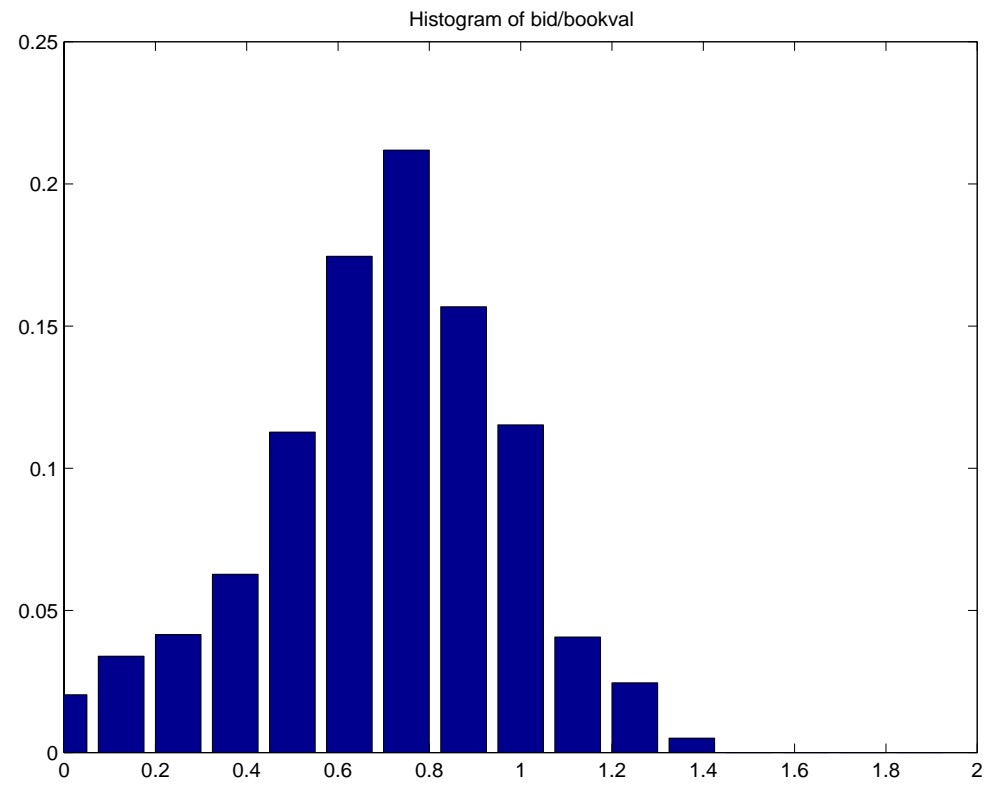

Figure 2:

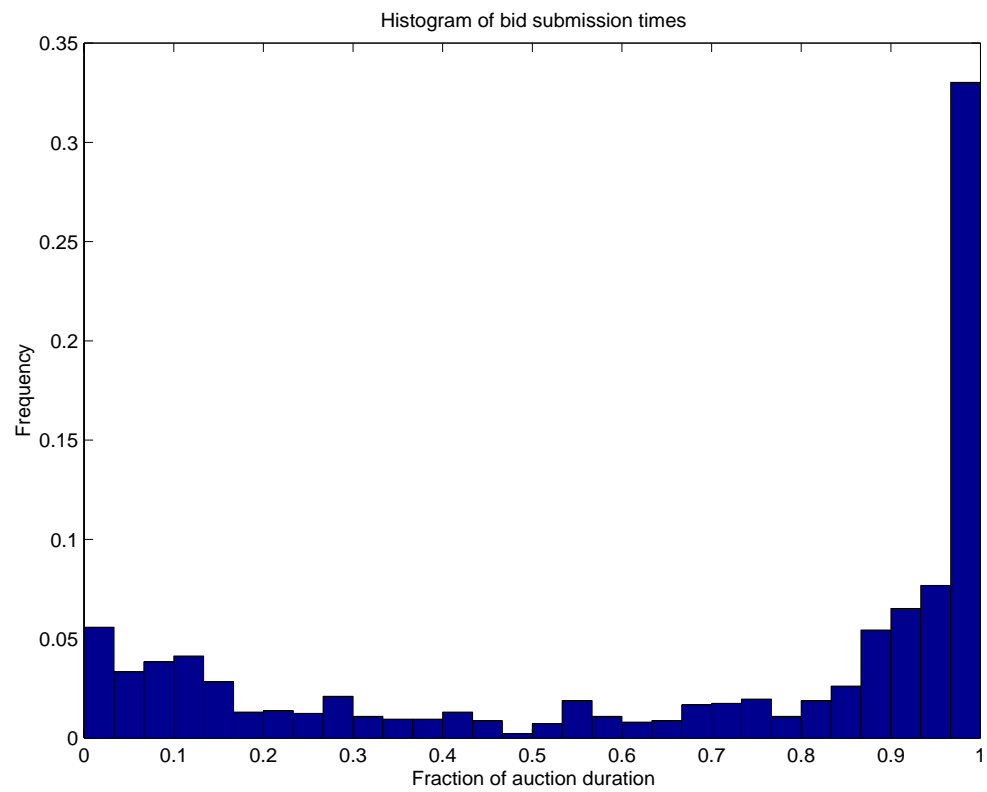


Figure 3:

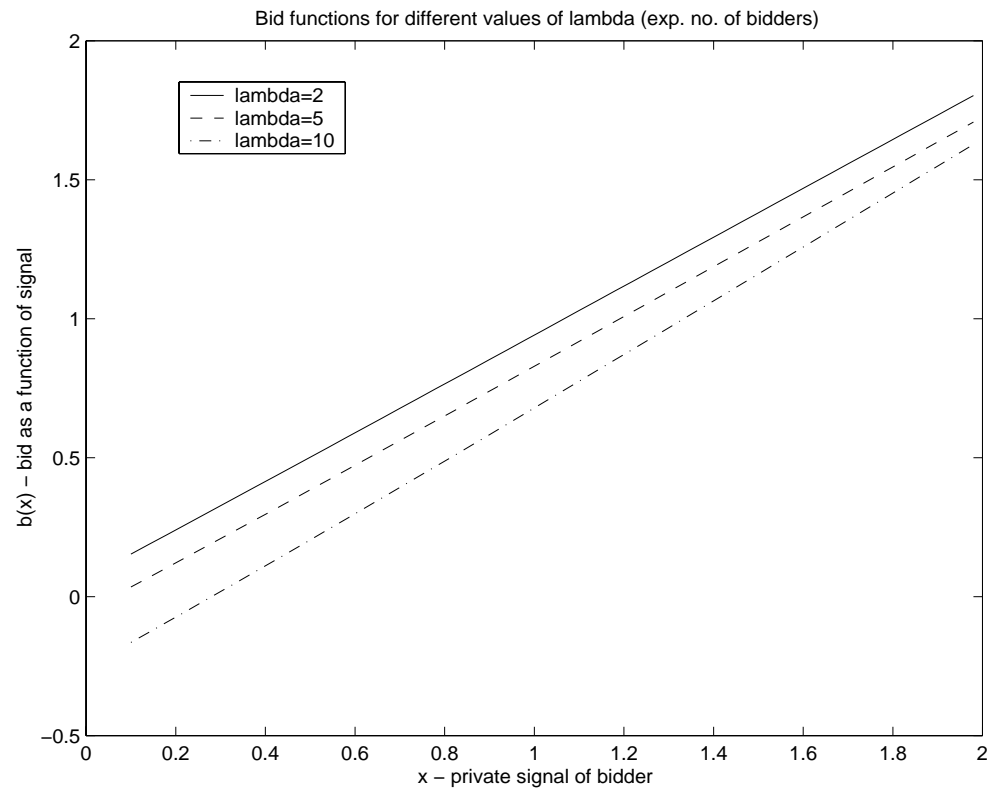

Figure 4:

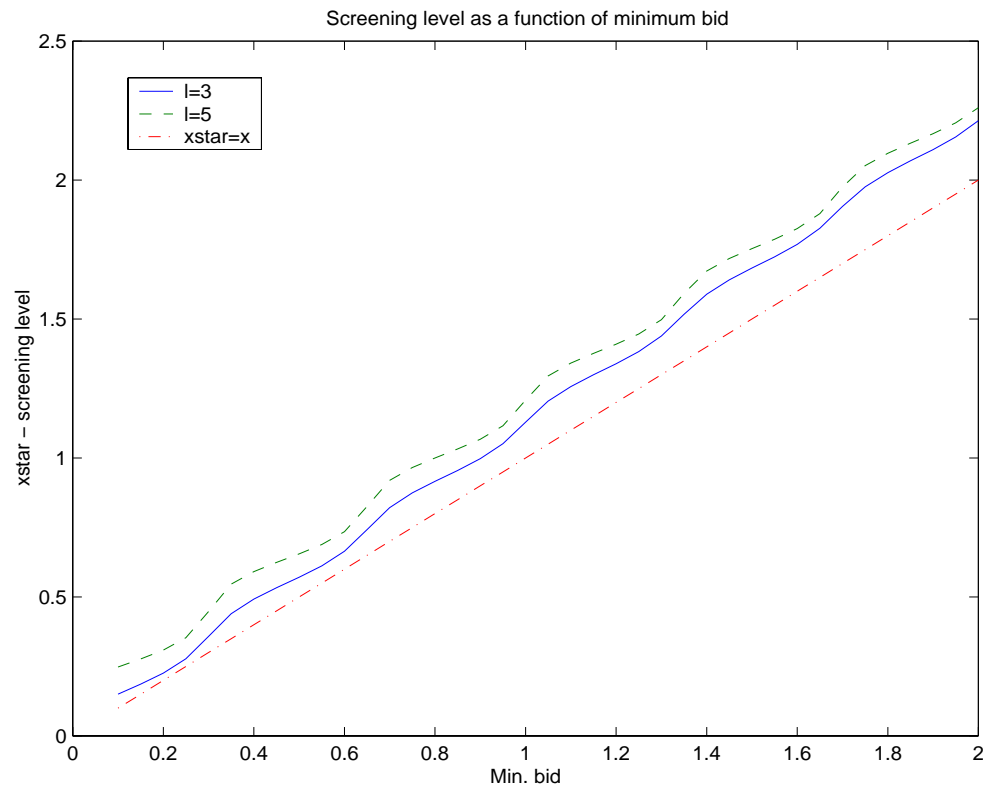


Figure 5:

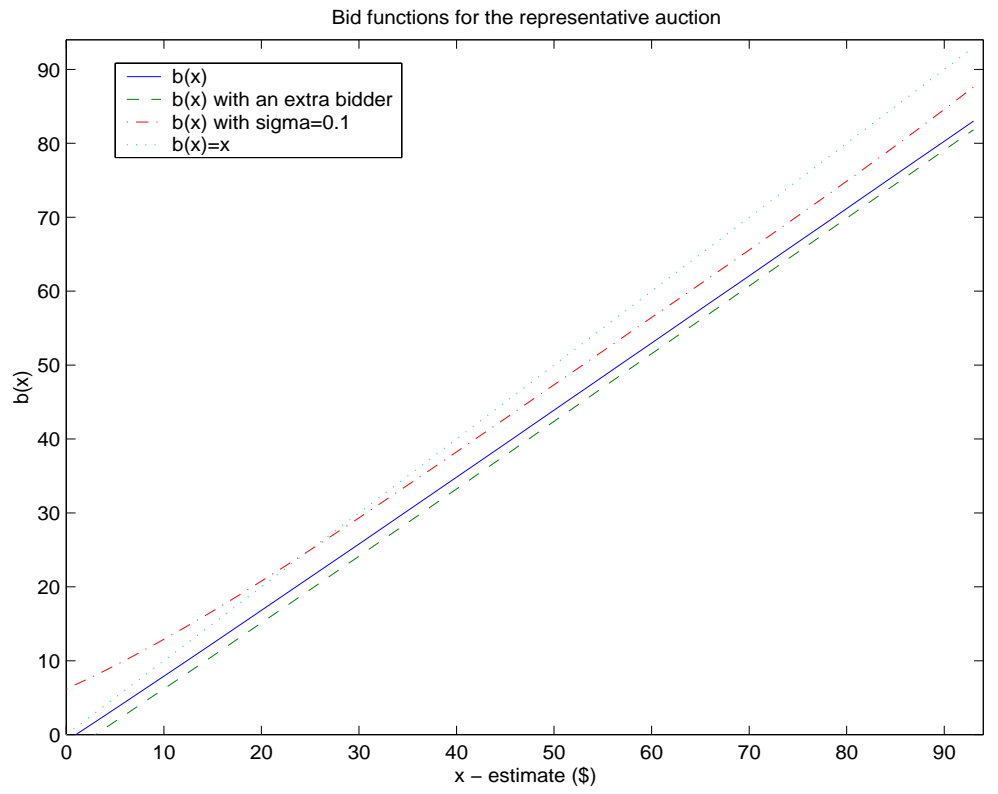

Figure 6:
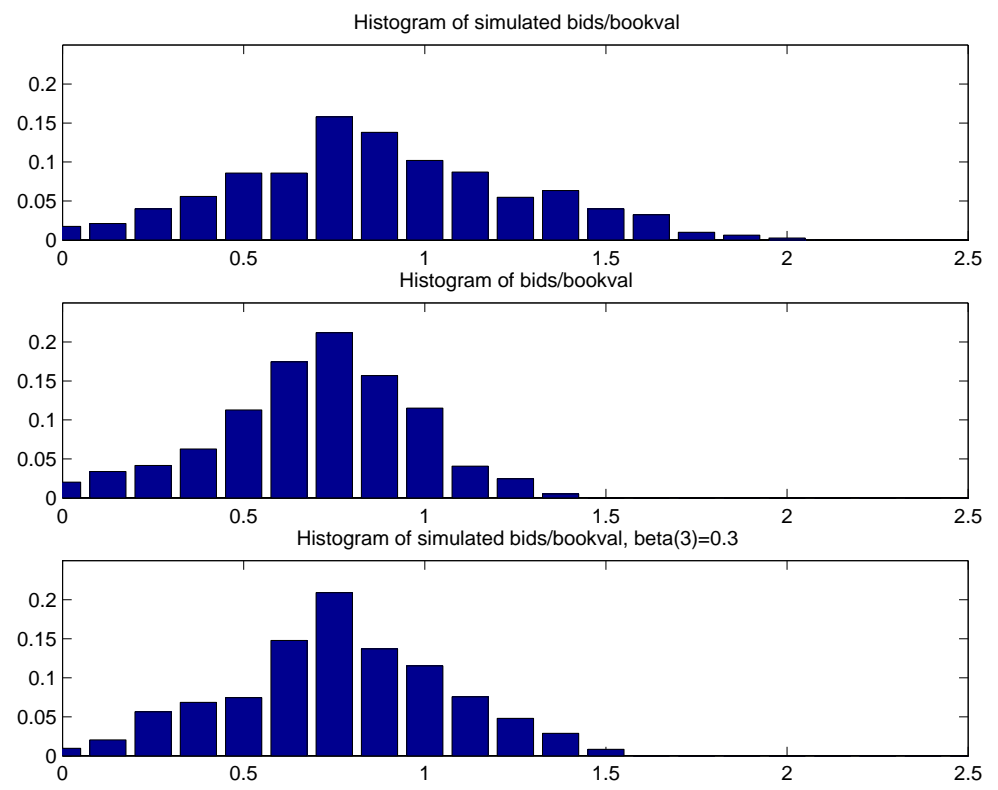
Figure 7:
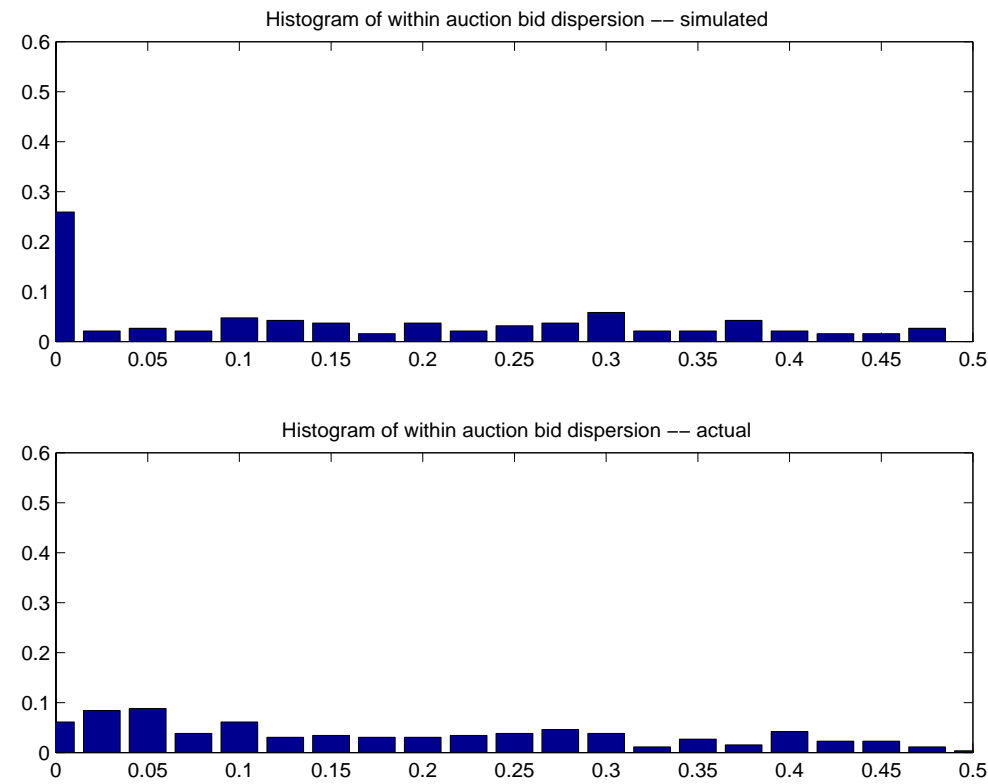

Figure 8: Expected revenue difference between secret and posted reserve schemes

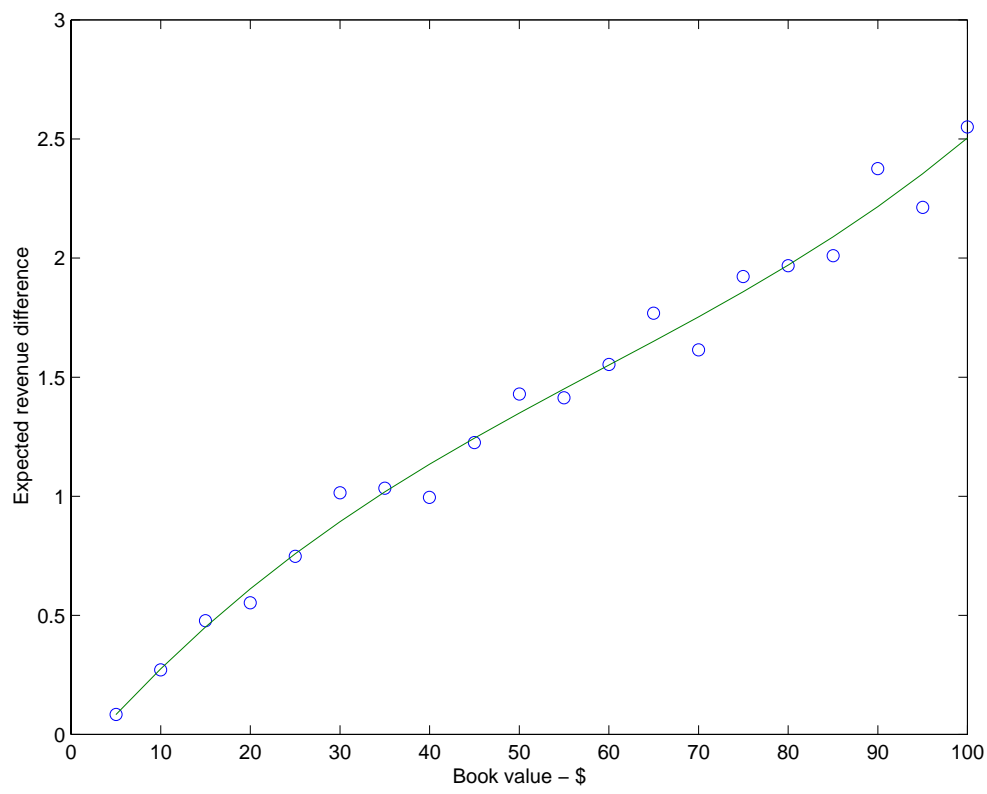


Figure 9: Sale probabilities for secret and posted reserve schemes

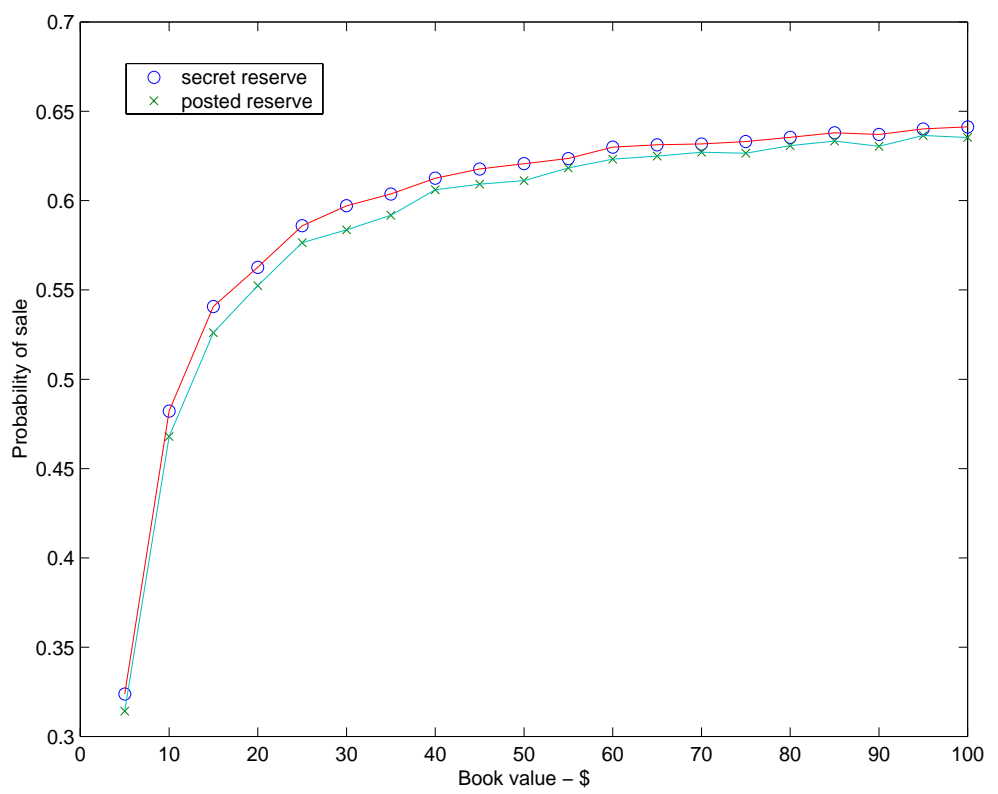

